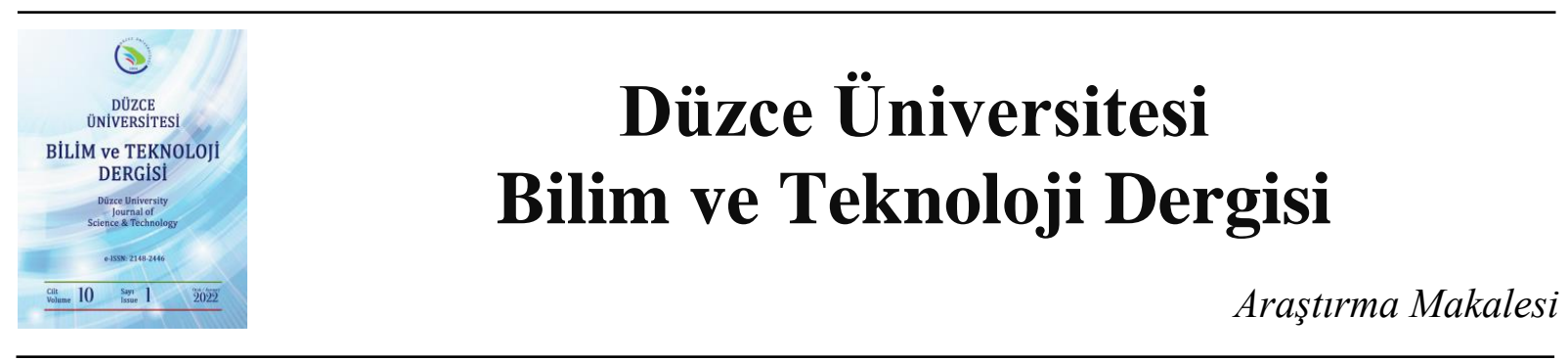

\title{
2,3-Di(tiyofen-3-il)piperazin Monomerlerinin Ultrases Destekli Sentezi, İletken Polimerlerinin Hazırlanması ve Süperkapasitör Davranışlarının İncelenmesi
}

\author{
Deniz YİĞİT ${ }^{a}{ }^{*}$ \\ ${ }^{a}$ Eczacılık Temel Bilimleri Ana Bilim Dal, Eczacılık Fakültesi, Lokman Hekim Üniversitesi, Ankara, TÜRKIYYE \\ * Sorumlu yazarin e-posta adresi: deniz.yigit@lokmanhekim.edu.tr
}

DOI: 10.29130/dubited.944357

\begin{abstract}
ÖZ
$\mathrm{Bu}$ çalışmada, 2,3-di(tiyofen-3-il)piperazin esaslı iletken polimer türevlerinin elektrokimyasal yük depolama özellikleri incelenmiştir. Bu amaçla, ilk önce, ultrases destekli bir yöntem kullanılarak 2,3-di(tiyofen-3il)piperazin halka sistemine sahip yeni elektroaktif monomerlerin sentezi gerçekleştirilmiştir. 2,3-Di(tiyofen-3il)piperazin monomerleri elektrokimyasal olarak paslanmaz çelik substrat yüzeylerinde polimerleştirilmiş ve poli(2,3-di(tiyofen-3-il)piperazin (PTTP) ve poli(2,3-di(tiyofen-3-il)dekahidrokinoksalin (PTTQ) esaslı redoks aktif elektrot malzemeleri hazırlanmıştır. PTTP ve PTTQ redoks aktif malzemelerinin kapasitif performansları dönüşümlü voltametri $(\mathrm{CV})$, galvanostatik şarj-deşarj $(\mathrm{GCD})$ ve elektrokimyasal impedans spektroskopi (EIS) teknikleri kullanılarak araştırılmışıı. PTTP ve PTTQ esaslı elektrot malzemeleri 2,5 $\mathrm{mAcm}^{-2}$ sabit akım yoğunluğunda $175 \mathrm{Fg}^{-1}$ ve $198 \mathrm{Fg}^{-1}$ spesifik kapasitans değerlerine ulaşmıştır. Ayrıca, PTTP ve PTTQ, sırasıyla, $70,2 \mathrm{Whkg}^{-1}$ ve $87,1 \mathrm{Whkg}^{-1}$ enerji yoğunluğu değerleri ile $7 \mathrm{kWkg}^{-1}$ ve $6,2 \mathrm{kWkg}^{-1}$ güç yoğunluğu değerleri sergilemiştir. Bunun yanı sıra, PTTP ve PTTQ elektrot malzemeleri 10000 şarj-deşarj döngüsü sonunda $\% 80$ ve $\% 87,5$ gibi oldukça yüksek uzun döngü ömrü kararlılıkları göstermiştir. Kapasitif performans test sonuçları PTTP ve PTTQ redoks aktif elektrot malzemelerinin yüksek performanslı pratik süperkapasitör uygulamalarında kullanılabilecek potansiyele sahip ümit vaat eden elektrot malzemeleri olduğunu ortaya koymuştur.
\end{abstract}

Anahtar Kelimeler: Ultrases destekli sentez, Poli(2,3-di(tiyofen-3-il)piperazin türevleri, Illetken polimerler, Redoks aktif elektrot malzemeleri, Süperkapasitörler

\section{Ultrasound Assisted Synthesis of 2,3-di(thiophene-3-yl)piperazine Monomers, Preparation of Their Conducting Polymers and Investigation of Their Supercapacitor Behaviors}

\begin{abstract}
In this study, the electrochemical charge storage properties of poly(2,3-di(thiophene-3-yl)piperazine)-based conducting polymer derivatives were investigated for supercapacitor applications. For this purpose, novel 2,3di(thiophene-3-yl)piperazine electroactive monomers were sonochemically synthesized and they were electrochemically polymerized on stainless steel substrates to prepare poly(2,3-di(thiophene-3-yl)piperazine (PTTP) and poly(2,3-di(thiophene-3-yl)decahydroquinoxaline (PTTQ)-based redox-active electrode materials. The capacitive performances of PTTP and PTTQ were investigated by cyclic voltammetry (CV), galvanostatic charge-discharge (GCD) and electrochemical impedance spectroscopy (EIS) techniques. PTTP and PTTQ redoxactive electrode materials achieved the specific capacitances of $175 \mathrm{Fg}^{-1}$ and $198 \mathrm{Fg}^{-1}$ at a constant current density of $2.5 \mathrm{mAcm}^{-2}$. PTTP and PTTQ electrodes also delivered the energy densities of 70,2 $\mathrm{Whkg}^{-1}$ and $87,1 \mathrm{Whkg}^{-1}$ and the power densities of $7 \mathrm{kWkg}^{-1}$ and $6,2 \mathrm{kWkg}^{-1}$. Besides, PTTP and PTTQ exhibited high long-term cycling stabilities ( $80 \%$ and $87,5 \%$ capacitance retentions). The results of capacitive performance tests reveal that PTTP and PTTQ electrode materials are promising redox-active materials for high-performance practical supercapacitor applications.
\end{abstract}

Keywords: Ultrasound-asssisted synthesis, Poly(2,3-di(thiophene-3-yl)piperazine) derivatives, Conducting polymers, Redox-active electrode materials, supercapacitors 


\section{GIRIS}

$\pi$-Konjuge organik iletken polimerler sahip oldukları iyi elektriksel iletkenlik, yüksek yük transfer kabiliyeti, kolay işlenebilirlik ve düşük maliyet gibi özelliklerinden dolayı günümüz plastik elektronik teknolojisinde sıklıkla tercih edilen önemli bir elektroaktif malzeme sınıfıdır. Organik iletken polimer türevleri son yirmi yıllık süreçte, elektrokromik cihazlar [1,2], organik fotovoltaik hücreler [3,4], organik 1şık saçan diyotlar $[5,6]$, transistörler $[7,8]$ ve sensörler $[9,10]$ başta olmak üzere farklı birçok teknolojide kendisine uygulama alanı bulmuştur. Son zamanlarda, $\pi$-konjuge organik iletken polimerlerin kullanıldığı bir diğer alan ise süperkapasitörlerdir. Süperkapasitörler klasik dielektrik kapasitörlerine ve pillere alternatif olarak geliştirilmiş yeni nesil elektrokimyasal enerji depolama sistemleri tanımlanmaktadır [11]. Süperkapasitörlerin güç yoğunlukları pillerden, enerji yoğunlukları ise dielektrik kapasitörlerinden daha yüksektir [12]. Akademik ve ticari nitelikteki süperkapasitör araştırmaları genel olarak değerlendirildiğinde, çalışmaların ağılıklı bir bölümünün süperkapasitörlerin enerji ve güç yoğunluklarını artırabilecek yeni elektrot malzemelerinin üretilmesi üzerinde yoğunlaştığı görülmektedir.

Karbon esasl1 malzemeler (karbon nanotüpler, karbon nanofiberler ve grafenler) [13-15], geçiş metal oksitleri $\left(\mathrm{TiO}_{2}, \mathrm{SnO}_{2}, \mathrm{NiO}, \mathrm{RuO}_{2}, \mathrm{~V}_{2} \mathrm{O}_{5}\right.$ ve $\left.\mathrm{MnO}_{2}\right)$ [16-21] ve $\pi$-konjuge organik iletken polimer türevleri [22] süperkapasitör uygulamalarında elektrot malzemesi olarak kullanılan önemli elektroaktif türlerdir. Farklı elektrokimyasal süreçler üzerinden yük depolayan bu üç ana malzeme sınıfi içerisinde, iletken polimerler, yüksek yük depolama kapasiteleri, iyi elektriksel iletkenlikleri, yüksek enerji yoğunlukları, uzun kimyasal kararlılıkları, kolay üretim süreçleri, iyi esneklik özellikleri gibi önemli avantajlarından dolayı ön plana çıkmaktadır (Tablo 1).

Tablo 1. Süperkapasitör uygulamalarında kullanılan elektroaktif malzeme türleri ve özellikleri

\begin{tabular}{cccc}
\hline $\begin{array}{c}\text { Kapasitif Performans } \\
\text { Parametresi }\end{array}$ & $\begin{array}{c}\text { Karbon esaslı } \\
\text { elektroaktif malzemeler }\end{array}$ & $\begin{array}{c}\text { Geçiş Metal } \\
\text { Oksit Türevleri }\end{array}$ & $\begin{array}{c}\text { Illetken Polimer } \\
\text { Türevleri }\end{array}$ \\
\hline Redoks kapasitans1 & Düşük & Yüksek & Yüksek \\
\hline Enerji yoğunluğu & Düşük & Orta & Orta \\
\hline Güç yoğunluğu & Yüksek & Düşük & Orta \\
\hline Elektriksel iletkenlik & Yüksek & Düşük & Yüksek \\
\hline Kimyasal kararlılık & Yüksek & Düşük & Yüksek \\
\hline Döngü ömrü & Yüksek & Orta & Orta \\
\hline Esneklik & Orta & Düşük & Yüksek \\
\hline Maliyet & Düşük & Yüksek & Düşük \\
\hline Üretim kolaylığ1 & Orta & Düşük & Yüksek \\
\hline
\end{tabular}

Süperkapasitör uygulamalarında, bugüne kadar, polianilin [23,24], polipirol [25,26], politiyofen $[27,28]$ ve polikarbozol [29,30] gibi farklı iletken polimer türevleri elektroaktif malzeme olarak kullanılmıştır. $\mathrm{Bu}$ tür elektroaktif malzemeler ile $110-640 \mathrm{Fg}^{-1}$ arasındaki yük depolama kapasitelerine (spesifik kapasitans, $\mathrm{C}_{\text {spec }}$ ) erişilmiştir. $\mathrm{Bu}$ iletken polimer türevleri arasında, politiyofenler, akım toplayıcı substratlar ile güçlü ve kararlı etkileşim kurabilme, uygun morfolojik yapı, hızlı yükleme/boşalma oranı, geniş potansiyel aralıklarında işlevsellik gösterebilme ve hem anot (p-doping) hem de katot (n-doping) malzemesi olarak kullanılabilme gibi özellikleri sayesinde süperkapasitör uygulamalarında en sık tercih edilen elektroaktif malzeme sınıfı haline gelmiştir [31]. Diğer taraftan, hızla gelişen yeni nesil elektronik teknolojilerinin enerji gereksinimlerinin karşılanabilmesi için yüksek yük depolama kapasitesi, güç ve enerji yoğunluklarına erişebilecek potansiyele sahip yeni elektroaktif malzemelerin üretilmesi ve süperkapasitör özelliklerinin incelenmesi bu alandaki en önemli ihtiyaçlardan birisidir. Bu bağlamda, literatürde bilinen örneklerden farklı kimyasal yapılara sahip yeni iletken polimer türevlerinin tasarımının ve sentezinin, süperkapasitör uygulamalarında kullanılabilecek nitelikteki elektroaktif malzeme çeşitliliğine büyük ölçüde katkı sağlayacağı değerlendirilmektedir. 
Bu çalışma kapsamında, ultrases destekli basit ve etkili bir yöntem kullanılarak 2,3-di(tiyofen-3il)piperazin yapısındaki elektroaktif monomerlerin sentezi gerçekleştirilmiştir. Sentezlenen monomerlerin kimyasal yapıları FTIR, ${ }^{1} \mathrm{H}-$ ve ${ }^{13} \mathrm{C}-\mathrm{NMR}$, MS ve element analizi teknikleri ile aydınlatılmıştır. 2,3-Di(tiyofen-3-il)piperazin halka yapısına sahip monomerler elektrokimyasal davranışlarının incelenmesinin ardından sabit potansiyel elektroliz tekniği ile paslanmaz çelik substrat yüzeylerinde doğrudan polimerleştirilerek iletken polimer esaslı yeni elektrot malzemeleri hazırlanmıştır. Söz konusu elektroaktif yüzeylerin kimyasal yapıları ve morfolojik özellikleri FTIR, element analizi ve taramalı elektron mikroskopi (SEM) yöntemleri kullanılarak karakterize edilmiştir. Poli(2,3-di(tiyofen-3-il)piperazin) esaslı redoks aktif elektrot malzemelerinin yük depolama kapasiteleri, enerji ve güç yoğunluğu gibi süperkapasitif davranışlarını yansıtan elektrokimyasal özellikleri ise dönüşümlü voltametri $(\mathrm{CV})$, galvanostatik şarj-deşarj (GCD) ve elektrokimyasal impedans spektroskopisi (EIS) teknikleri ile incelenmiştir.

\section{MATERYAL VE YÖNTEM}

\section{A. MALZEME VE CIHAZLAR}

3-Tiyofenkarboksaldehit (\%98), 1,2-diaminoetan (ReagentPlus $\geq \% 99.0$ ), 1,2-siklohekzandiamin, çinko tozu ve trifloroasetik asit Sigma Aldrich firmasından temin edilmiştir. Ticari olarak temin edilen tüm kimyasallar herhangi bir ön saflaştırma aşamasından geçirilmeden direkt olarak kullanılmıştır. Elektrokimyasal çalışmalarda çözücü olarak kullanılan asetonitril (ACN) 4 saat boyunca $\mathrm{P}_{2} \mathrm{O}_{5}$ varlığında geri soğutucu altında kaynatılmış ve daha sonrasında fraksiyonel damıtma tekniği ile damıtılmıştır. Saflaştırılan ACN azot atmosferi altında ve 4A moleküler elek varlığında muhafaza edilmiştir. $\mathrm{LiClO}_{4}$ destek elektroliti her elektrokimyasal çalışma öncesinde $80^{\circ} \mathrm{C}^{\prime}$ ye ayarlanmış etüvde 8 saat boyunca bekletilerek muhtemel nemden arındırılmıştır. Yerel bir üreticiden temin edilen paslanmaz çelik levha (Type 316 Stainless Steel, 0,5 mm kalınlık) lazer kesim tekniği kullanılarak uygun boyutlardaki $(1 \mathrm{~cm}$ en, $1 \mathrm{~cm}$ boy) akım toplayıcı substratlar haline dönüştürülmüştür.

Ultrases destekli sentez çalışmalarında Sonic Ultrasonic Processors VCX Series/VCX 750 ultrases probu kullanılmıştır. Ara ürünlerin ve hedef monomerlerin FTIR spektrumları Perkin Elmer Spectrum 100 spektrometre, kütle spektrumları Agilent Technologies 6890N GC System/Agilent Technologies 5975B VLMSD kütle spektrometre, ${ }^{1} \mathrm{H}$ ve ${ }^{13} \mathrm{C}$ NMR spektrumları ise Varian-Mercury $400 \mathrm{MHz}$ Digital Fourier-Transform (FT) NMR spektometre ile kaydedilmiştir. Element analizleri Eurovector CHNS Elemental Analyser kullanılarak gerçekleştirilmiştir. Paslanmaz çelik substrat yüzeylerine kaplanmış olan iletken polimer filmlerin morfolojik özellikleri Zeiss Ultra Plus FE-SEM/EVO $40500 \mathrm{~V}$ taramalı elektron mikroskopu ile incelenmiştir. Tüm elektrokimyasal çalışmalar Radiometer VoltaLab PST50 Potentiostat/Galvanostat-High Voltage Booster $100 \mathrm{~V}$ ve Princeton Applied Reserach PAR-2273 Potentiostat/Galvanostat kullanılarak gerçekleştirilmiştir.

\section{B. MONOMER SENTEZI}

\section{A. 1. N,N-Bis(tiyofen-3-ilmetilen)-1,2-diamin Türevlerinin Genel Sentez Yöntemi}

$50 \mathrm{~mL}$ 'lik bir balona 3-tiyofenkarboksaldehit ( $0.4578 \mathrm{~g}, 4 \mathrm{mmol}$, \%98 saflık) konularak $25 \mathrm{~mL}$ metanol içerisinde tamamen çözülmüştür. Daha sonra, bir damlatma hunisi yardımıyla diamin bileşiği $(1,2-$ diaminoetan veya 1,2-siklohekzandiamin, $2 \mathrm{mmol}$ ) metanol çözeltisi üzerinde parça parça ilave edilmiş̧tir. Elde edilen sarı renkli metanol çözeltisi 8 saat boyunca oda sıcaklığında karıştırıldıktan sonra metanol indirgen basınç altında damıtılarak geri kazanılmıştır. Bu işlemlerin ardından elde edilen katı ham ürün etanol-su (1:1) karışımından kristallendirilerek saflaştırılmıştır.

$\left(N^{l}, E, N^{2}, E\right)$-Bis(tiyofen-3-ilmetilen)etan-1,2-diamin (3a): Açık sarı renkli katı ürün (0.49 g, 1.96 mmol, $\% 98$, e.n. $\left.=97^{\circ} \mathrm{C}\right)$. MS (EI) m/z $(\%) \mathrm{C}_{12} \mathrm{H}_{12} \mathrm{~N}_{2} \mathrm{~S}_{2}$ için hesaplanan: 286.36; bulunan $248(\mathrm{M}+, 5), 219(5)$, 
190 (5), 139 (100), 124 (60), 110 (50), 97 (70), 45 (10). FTIR (ATR) $v_{\max } / \mathrm{cm}^{-1} 3101$ (oş, aromatik C$\mathrm{H}$ gerilmesi), 3084 (oş, imin C-H gerilmesi), 2920, 2829 (z, alifatik C-H gerilmeleri), 1640 (g, imin $\mathrm{C}=\mathrm{N}$ gerilmesi), 1425, 1354, 1332 (oş, alifatik $\mathrm{C}-\mathrm{H}$ eğilmeleri). Element analizi: $\mathrm{C}_{12} \mathrm{H}_{12} \mathrm{~N}_{2} \mathrm{~S}_{2}$ için hesaplanan C \%58,03; H \%4,87; N \%11,28, bulunan: C \%57,89; H \%4,72; N \%11,01.

$\left(N^{l}, E, N^{2}, E\right)$-Bis(tiyofen-3-ilmetilen)siklohekzan-1,2-diamin (3b): Bej renkli kat1 ürün $(0.53 \mathrm{~g}, 1.74$ mmol, \%87, e.n. $\left.=170-175^{\circ} \mathrm{C}\right)$. MS (EI) $\mathrm{m} / \mathrm{z}(\%) \mathrm{C}_{16} \mathrm{H}_{18} \mathrm{~N}_{2} \mathrm{~S}_{2}$ için hesaplanan: 302,45; bulunan $302(\mathrm{M}+$, 7), 259 (5), 205 (5), 193 (90), 162 (10), 136 (10), 112 (100), 97 (30). FTIR (ATR) $v_{\text {max }} / \mathrm{cm}^{-1} 3108$ (oş, aromatik C-H gerilmesi), 3093 (oş, imin C-H gerilmesi), 2924, 2851 (z, alifatik C-H gerilmeleri), 1637 (g, imin $\mathrm{C}=\mathrm{N}$ gerilmesi), 1451, 1402, 1338, 1300 (oş, alifatik $\mathrm{C}-\mathrm{H}$ eğilmeleri). Element analizi: $\mathrm{C}_{18} \mathrm{H}_{18} \mathrm{~N}_{2} \mathrm{~S}_{2}$ için hesaplanan $\mathrm{C} \% 63,54 ; \mathrm{H} \% 6,00 ; \mathrm{N} \% 9,26$, bulunan: $\mathrm{C} \% 63,69 ; \mathrm{H} \% 5,88 ; \mathrm{N} \% 9,56$.

\section{A. 2. 2,3-Di(tiyofen-3-il)piperazin Türevlerinin Genel Sentez Yöntemi}

N,N-bis(tiyofen-3-ilmetilen)-1,2-diamin türevi (3a veya 3b, 1,53 mmol) ve çinko tozu $(0,2 \mathrm{~g}, 3,054$ mmol) karışımı $50 \mathrm{~mL}$ 'lik bir ultrasonikasyon kabına konularak üzerine taze damıtılmış $20 \mathrm{~mL}$ diklorometan ilave edilmiştir. Elde edilen süspansiyon azot atmosferi altında ve oda sıcaklığında 15 dakika boyunca şiddetli bir şekilde karıştırılmıştır. Bu işlemin ardından, reaksiyon kabı buz banyosuna yerleştirilerek süspansiyon içerisine damla damla trifloroasetik asit $(0,34 \mathrm{~g}, 3,064 \mathrm{mmol})$ ilavesi yapılmıştır. Elde edilen karışım, $50^{\circ} \mathrm{C}$ sıcaklıkta Sonic VCX Series/VCX 750 ultrasonik prob kullanılarak 30 dakika boyunca ultrases dalgalarına maruz bırakılmıştır $(500 \mathrm{~W}, 20 \mathrm{kHz})$. Reaksiyonun tamamlanmasının ardından çinko kalıntıları süzülerek organik fazdan ayrılmışırı. Diklorometan döner buharlaştırıcıdan geri kazanılmış ve elde edilen yağımsı kalıntı buzlu suya $(20 \mathrm{~mL})$ dökülmüştür. Doygun $\mathrm{NaHCO}_{3}$ çözeltisi ile sulu fazın pH değeri 9-10 arasına ayarlanmıştır. Son olarak, bazik çözelti kloroform (4 x $20 \mathrm{~mL}$ ) ile ekstrakte edilerek $\mathrm{Na}_{2} \mathrm{SO}_{4}$ üzerinden kurutulmuştur. Çözücünün indirgen basınç altında geri kazanılmasının ardından elde edilen yağımsı ham ürün hekzan/etil asetat (4:1, v/v) karışımı kullanılarak kolon kromatografisi tekniği ile saflaştırılmıştır.

2,3-Di(tiyofen-3-il)piperazin (TTP): Açık kahverengi katı ürün $(0,36 \mathrm{~g}, 1,42 \mathrm{mmol}, \% 93$, e.n. $=76$ $\left.78^{\circ} \mathrm{C}\right) .{ }^{1} \mathrm{H}$ NMR $\left(400 \mathrm{MHz}, \mathrm{CDCl}_{3}\right) \delta_{\mathrm{H}} / \mathrm{ppm}: 2,0\left(\mathrm{y}, 2 \mathrm{H}\right.$, Piperazin N-H), 3,0 (pç, 4H, Piperazin, $-\mathrm{C}_{2}{ }^{-}$ ), 3,75 (t, 2H, Piperazin, - $\mathrm{CH}-$ ), 6,65 (ii, 2H, $J=4,6 \mathrm{~Hz}$ ve $J=1,2 \mathrm{~Hz}$, Tiyofen-H), 6,9 (ii, 2H, $J=4 \mathrm{~Hz}$ ve $J=1,2 \mathrm{~Hz}$, Tiyofen-H), 7,05 (ii, $2 \mathrm{H}, J=5 \mathrm{~Hz}$ ve $J=2,8 \mathrm{~Hz}$, Tiyofen-H). ${ }^{13} \mathrm{C}$ NMR $\left(400 \mathrm{MHz}, \mathrm{CDCl}_{3}\right.$ ) $\delta_{\mathrm{C}}$ ppm: 45,3 (Piperazin- $\mathrm{CH}_{2-}$ ), 74,8 (Piperazin- $\underline{\mathrm{CH}}$-), 120,7 (Tiyofen-C2), 125,6 (Tiyofen-C5), 127,2 (Tiyofen-C4), 140,6 (Tiyofen-C3). MS (EI) m/z (\%) $\mathrm{C}_{12} \mathrm{H}_{14} \mathrm{~N}_{2} \mathrm{~S}_{2}$ için hesaplanan: 250,4; bulunan 250,1 (M+, 40), 138,1 (40), 125,1 (50), 110,1 (100), 97 (60), 80,1 (15). FTIR (ATR) $v$ max $/ \mathrm{cm}^{-1} 3243$ (oş, piperazin N-H gerilmesi), 3102 (oş, aromatik C-H gerilmeleri), 2946, 2906 (z, alifatik C-H gerilmeleri), 1625 (ş, piperazin N-H eğilmesi), 1451, 1402, 1338, 1300 (o, alifatik C-H eğilmeleri), 1268 (oş, piperazin -C-N-C- gerilmesi). Element analizi: $\mathrm{C}_{12} \mathrm{H}_{14} \mathrm{~N}_{2} \mathrm{~S}_{2}$ için hesaplanan $\mathrm{C} \% 57,56 ; \mathrm{H} \% 5,64 ; \mathrm{N}$ $\% 11,19$, bulunan: C \%57,24; $\mathrm{H} \% 5,38 ; \mathrm{N} \% 10,87$.

2,3-Di(tiyofen-3-il)dekahidrokinoksalin (TTQ): Kahverengi kat1 ürün $(0,39 \mathrm{~g}, 1,29 \mathrm{mmol}$, \%84, e.n.= 120-123 ${ }^{\circ} \mathrm{C}$ ). ${ }^{1} \mathrm{H}$ NMR (400 MHz, $\left.\mathrm{CDCl}_{3}\right) \delta_{\mathrm{H}} / \mathrm{ppm}: 1,4$ (pç, 4H, Siklohekzil $\left.-\mathrm{C}_{2}{ }^{-}\right), 1,68$ (pç, 4H, Siklohekzil - $\mathrm{CH}_{2}-$ ), 2,4 (y, 2H, Piperazin N-H), 2,6 (pç, 2H, Siklohekzil - Cㅂ-H-), 4,0 (t, 2H, Piperazin, CH-), 6,8 (i, 2H, J=4,8 Hz, Tiyofen-H), 7,12 (i, 2H, $J=1,6 \mathrm{~Hz}$, Tiyofen-H), 7,18 (ii, 2H, $J=4,6 \mathrm{~Hz}$ ve $J=2,8 \mathrm{~Hz}$, Tiyofen-H). ${ }^{13} \mathrm{C}$ NMR $\left(400 \mathrm{MHz}, \mathrm{CDCl}_{3}\right) \quad \delta_{\mathrm{C}} / \mathrm{ppm}: 24,4$ (Siklohekzil- $\left.\mathrm{CH}_{2}-\right), 31,5$

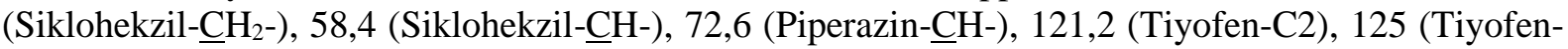
C5), 129,2 (Tiyofen-C4), 139,6 (Tiyofen-C3). MS (EI) m/z (\%) $\mathrm{C}_{16} \mathrm{H}_{20} \mathrm{~N}_{2} \mathrm{~S}_{2}$ için hesaplanan: 304,5; bulunan 304,1 (M+, 60), 207,1 (10), 193,1 (60), 165 (10), 112 (100), 96,1 (25). FTIR (ATR) $v_{\max } / \mathrm{cm}^{-}$ ${ }^{1} 3273$ (oş, piperazin N-H gerilmesi), 3104 (oş, aromatik C-H gerilmeleri), 2950, 2808 (z, alifatik C-H gerilmeleri), 1620 (ş, piperazin N-H eğilmesi), 1451, 1425, 1366, 1290 (g, alifatik C-H eğilmeleri), 1256 (oş, piperazin -C-N-C- gerilmesi). Element analizi: $\mathrm{C}_{16} \mathrm{H}_{20} \mathrm{~N}_{2} \mathrm{~S}_{2}$ için hesaplanan $\mathrm{C} \% 63,12 ; \mathrm{H} \% 6,62 ; \mathrm{N}$ $\% 9,20$, bulunan: C \%63,47; $\mathrm{H} \% 6,47 ; \mathrm{N} \% 8,85$. 


\section{ELEKTROKIMYYASAL KARAKTERIZASYON ÇALIŞMALARI}

TTP ve TTQ monomerlerinin elektrokimyasal redoks özellikleri CV tekniği kullanılarak incelenmiştir. Monomerlerin dönüşümlü voltamogramları, platin disk çalışma elektrotu, platin disk karşıt elektrot ve $\mathrm{Ag} / \mathrm{AgCl}$ referans elektrottan oluşan üç elektrot sistemi ile $0,1 \mathrm{~N} \mathrm{LiClO}_{4} / \mathrm{ACN}$ destek elektroliti içerisinde $0-2 \mathrm{~V}$ potansiyel aralı̆̆ında kaydedilmiştir. Platin disk çalışma elektrot yüzeyine kaplanan poli(2,3-di(tiyofen-3-il)piperazin (PTTP) ve poli(2,3-di(tiyofen-3-il)dekahidrokinoksalin (PTTQ) esasl1 iletken polimer filmlerin elektrokimyasal özellikleri ise tek taramalı dönüşümlü voltametri çalışmaları ile karakterize edilmiştir. Bu çalışmalarda platin disk elektrot karşıt elektrot, $\mathrm{Ag} / \mathrm{AgCl}$ elektrot referans elektrot olarak kullanılmıştır. İletken polimer filmlerin anodik bölgedeki redoks davranışları $0-2 \mathrm{~V}$, katodik bölgedeki redoks davranışları $0--2,0 \mathrm{~V}$ potansiyel aralıklarında $100 \mathrm{mVs}^{-1}$ tarama hızında incelenmiştir.

\section{ELEKTROT MAZLEMELERININ HAZIRLANMASI}

PTTP ve PTTQ esaslı redoks aktif elektrot malzemeleri sabit potansiyel elektrolizi tekniği ile hazırlanmıştır. $0,1 \mathrm{M} \mathrm{LiClO}_{4} / \mathrm{ACN}$ destek elektroliti içerisinde $0,05 \mathrm{M}$ monomer konsantrasyonunda $200 \mathrm{mCcm}^{-2}$ yük yoğunluğunda gerçekleştirilen elektroliz işlemleri sonucunda paslanmaz çelik çalışma elektrotlarının yüzeyleri PTTP ve PTTQ iletken polimer filmlerle kaplanmıştır. Sabit potansiyel elektroliz çalışmalarında paslanmaz çelik substratlara 115 saniye boyunca 1,72 V (PTTP film kaplaması için) ve $1,77 \mathrm{~V}$ (PTTQ film kaplaması için) monomer yükseltgenme potansiyelleri uygulanmıştır. Elektroliz işlemlerinin ardından PTTP ve PTTQ polimerik yüzeylere monomer bulunmayan destek elektroliti çözeltisi içerisinde 1 dakika boyunca - 0,5 V sabit negatif potansiyel uygulanmıştır. Son olarak, iletken polimer esaslı elektrot malzemeleri asetonitril/diklorometan karışımı birkaç kez yıkandıktan sonra $80^{\circ} \mathrm{C}$ 'deki etüvde 2 saat boyunca kurutulmuştur. Paslanmaz çelik substratların yüzeylerine kaplanmış PTTP ve PTTQ polimerik filmlerin kütlesi mikroanalitik terazi $(\Delta \mathrm{m}= \pm 0,001$ mg) yardımıyla belirlenmiştir. Polimerik filmlerin yapısal karakterizasyonu FTIR, morfolojik incelemeleri ise SEM teknikleri kullanılarak gerçekleştirilmiştir.

Poli(2,3-di(tiyofen-3-il)piperazin) (PTTP): FTIR (ATR) $v_{\max } / \mathrm{cm}^{-1} 3310-3256$ (y, piperazin N-H gerilmesi), 3108 (z, aromatik C-H gerilmesi), 2946-2906 (z, alifatik C-H gerilmesi), 1634 (oş, polikonjugasyon aromatik $-\mathrm{C}=\mathrm{C}$ - gerilmesi), 1480-1290 (g, alifatik $\mathrm{C}-\mathrm{H}$ eğilmesi).

Poli(2,3-di(tiyofen-3-il)dekahidrokinoksalin) (PTTQ): FTIR (ATR) $v_{\max } / \mathrm{cm}^{-1} 3338-3274$ (y, piperazin $\mathrm{N}-\mathrm{H}$ gerilmesi), 3100 (z, aromatik C-H gerilmesi), 2986-2864 (z, alifatik C-H gerilmesi), 1642 (oş, polikonjugasyon aromatik $-\mathrm{C}=\mathrm{C}$ - gerilmesi), 1447-1285 ( $\mathrm{g}$, alifatik $\mathrm{C}-\mathrm{H}$ eğilmesi).

\section{E. KAPASITIF PERFORMANS TESTLERİ}

PTTP ve PTTQ esaslı redoks aktif polimerik malzemelerin süperkapasitör özellikleri $0,5 \mathrm{M}$ $\mathrm{LiClO}_{4} / \mathrm{ACN}$ siv1 destek elektroliti ortamında iki elektrot konfigürasyonuna sahip simetrik bir elektrokimyasal test hücresi kullanılarak incelenmiştir. Bu test hücresinde iletken polimer kaplı redoks aktif malzemeler hem çalışma hem de karşıt elektrot olarak kullanılmıştır. Referans elektrot bağlantısı ise karşıt elektrot üzerinden gerçekleştirilmiştir. PTTP ve PTTQ esaslı elektrot malzemelerinin kapasitif özellikleri CV, GCD ve EIS teknikleri ile karakterize edilmiştir. Dönüşümlü voltamogramlar $0-1,85$ $\mathrm{V}$ potansiyel aralığında $10 \mathrm{mVs}^{-1}$ ile $250 \mathrm{mVs}^{-1}$ arasındaki farklı tarama hızlarında kaydedilmiştir. GCD testleri ise yine aynı potansiyel skalasında $2,5 \mathrm{mAcm}^{-2}$, den $12,5 \mathrm{mAcm}^{-2}$, ye artan akım yoğunluğunda gerçekleştirilmiştir. EIS çalışmaları $5 \mathrm{mV}$ rms amplitüd değerinde $10 \mathrm{kHz}$ ile $0,01 \mathrm{~Hz}$ frekans aralığında $0 \mathrm{~V}$ uygulama potansiyeli altında yürütülmüştür. PTTP ve PTTQ esaslı redoks aktif elektrotların simetrik süperkapasitör test hücrelerinde sergiledikleri yük depolama kapasiteleri $\left(\mathrm{C}_{\mathrm{spec}}, \mathrm{Fg}^{-1}\right)$, enerji $\left(\mathrm{SE}, \mathrm{Whkg}^{-1}\right)$ ve güç $\left(\mathrm{SP}, \mathrm{Wkg}^{-1}\right)$ yoğunlukları aşağıdaki formüller ile hesaplanmıştır. 


$$
\begin{aligned}
& \text { Cspec }=\frac{(I \times t d)}{\Delta \mathrm{V} \times \mathrm{mac}} \\
& S E=\frac{\left[\operatorname{Cspec} \times(\Delta \mathrm{V})^{2}\right)}{7,2} \\
& S P=\frac{(3600 \times S E)}{t d}
\end{aligned}
$$

Eşitliklerdeki I deşarj akım yoğunluğuna $\left(\mathrm{mAcm}^{-2}\right), \Delta \mathrm{V}$ deşarj işlemi sırasındaki potansiyel farkına (V), td deşarj zamanına (s) ve mac hem çalışma hem de karşıt elektrottaki toplam iletken polimer kütlesine (mg) karşılık gelmektedir.

Simetrik süperkapasitör hücrelerine ait teorik eşdeğer devre modellemeleri ZSimpWin 3.50 yazılımı kullanılarak kompleks doğrusal olmayan en küçük kareler yöntemi ile oluşturulmuştur.

\section{BULGULAR VE TARTISMA}

İletken polimer esaslı redoks aktif elektrot malzemelerinin hazırlanmasında kullanılacak olan TTP ve TTQ monomerlerinin sentezi basit ve etkili bir yöntem kullanılarak, ilk defa bu çalışma kapsamında gerçekleştirilmiştir. Hedef monomerlerin sentezi için geçiş metali varlı̆̆ındaki klasik dimin hidrodimerleşme reaksiyonunu temel alan ultrases destekli alternatif bir sentetik yöntem uygulanmıştır (Şekil 1). Ultrases dalgalarının metal reaktiflerin yüzeyini etkinleştirerek katalitik aktiviteyi artırdığ1 bilindiği için, klasik hidrodimerleşme yöntemi yerine sonokimyasal bir sentetik prosedür tercih edilerek hem reaksiyon verimlerinin artırılması hem de reaksiyon sürelerinin kısaltılması hedeflenmiştir [32]. Asit türü ve reaksiyon süresi gibi farklı reaksiyon parametrelerin incelendiği optimizasyon çalışmalarının sonuçları Tablo 2' de özetlenmiştir. Bu sonuçlar ultrases destekli hidrodimerleşme reaksiyonlarının güçlü bir organik asit olan trifloroasetik asit varlığında en yüksek ürün verimiyle gerçekleştiğini ortaya koymuştur. Diğer taraftan, reaksiyon sürelerinin 30 dakikanın üzerine çıkarıldığı denemelerde hidrodimerleşme ürünü oranının azaldığı, bununla birlikte imin indirgenme ürünlerinin meydana geldiği de tespit edilmiştir. Sentezlenen TTP ve TTQ monomerlerinin kimyasal yapıları FTIR, ${ }^{1} \mathrm{H}$ NMR, ${ }^{13} \mathrm{C}$ NMR, MS ve element analizi ile aydınlatılmıştır. Model bileşik olarak seçilen TTQ' nun ${ }^{1} \mathrm{H}$ NMR ve ${ }^{13} \mathrm{C}$ NMR spektrumları Şekil 2'de detaylı olarak incelenmiştir.

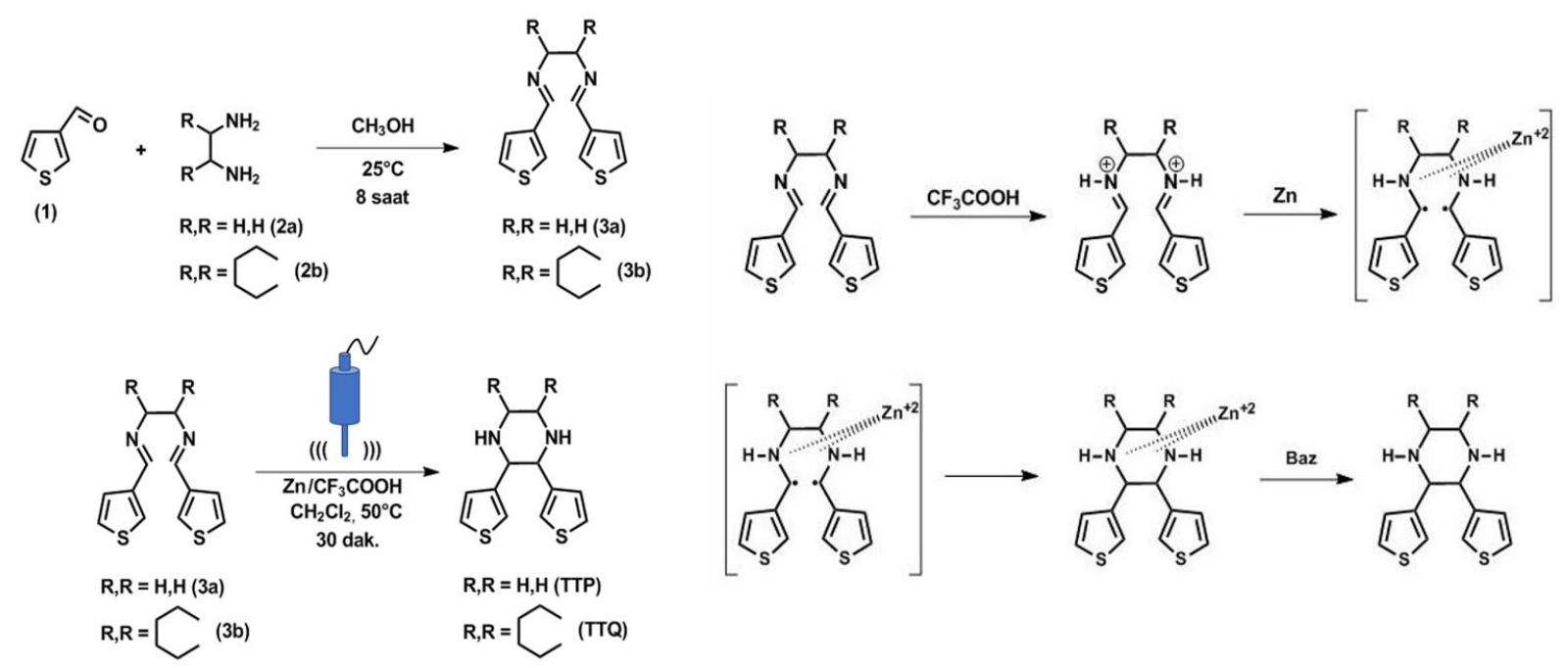

Şekil 1. 2,3-Di(tiyofen-3-il)piperazin türevi monomerlerin (TTP ve TTQ) sentez yöntemi ve metal katalizli indirgen hidrodimerleşme reaksiyonu mekanizması 
Tablo 2. TTP ve TTQ elektroaktif monomerlerinin sentezi için optimize edilen reaksiyon koşulları

Monomer Klasik Hidrodimerleşme Yöntemi $\quad$ Sonokimyasal Hidrodimerleşme Yöntemi

\begin{tabular}{|c|c|c|c|c|c|c|}
\hline & Asit & $\begin{array}{c}\text { Süre } \\
(\text { sa. })\end{array}$ & $\begin{array}{c}\text { Verim } \\
(\%)\end{array}$ & Asit & $\begin{array}{c}\text { Süre } \\
\text { (dak.) }\end{array}$ & $\begin{array}{c}\text { Verim } \\
(\%)\end{array}$ \\
\hline TTP & $\mathrm{CH}_{3} \mathrm{COOH}$ & 4 & 22 & $\mathrm{CH}_{3} \mathrm{COOH}$ & 5 & 26 \\
\hline TTP & $\mathrm{CH}_{3} \mathrm{COOH}$ & 6 & 42 & $\mathrm{CH}_{3} \mathrm{COOH}$ & 10 & 44 \\
\hline TTP & $\mathrm{CH}_{3} \mathrm{COOH}$ & 8 & 56 & $\mathrm{CH}_{3} \mathrm{COOH}$ & 15 & 53 \\
\hline TTP & $\mathrm{CH}_{3} \mathrm{COOH}$ & 10 & 62 & $\mathrm{CH}_{3} \mathrm{COOH}$ & 30 & 61 \\
\hline TTP & $\mathrm{CH}_{3} \mathrm{COOH}$ & 12 & 70 & $\mathrm{CH}_{3} \mathrm{COOH}$ & 45 & 61 \\
\hline TTP & $\mathrm{CH}_{3} \mathrm{SOOH}$ & 4 & 38 & $\mathrm{CH}_{3} \mathrm{SOOH}$ & 5 & 53 \\
\hline TTP & $\mathrm{CH}_{3} \mathrm{SOOH}$ & 6 & 51 & $\mathrm{CH}_{3} \mathrm{SOOH}$ & 10 & 61 \\
\hline TTP & $\mathrm{CH}_{3} \mathrm{SOOH}$ & 8 & 63 & $\mathrm{CH}_{3} \mathrm{SOOH}$ & 15 & 72 \\
\hline TTP & $\mathrm{CH}_{3} \mathrm{SOOH}$ & 10 & 72 & $\mathrm{CH}_{3} \mathrm{SOOH}$ & 30 & 78 \\
\hline TTP & $\mathrm{CH}_{3} \mathrm{SOOH}$ & 12 & 78 & $\mathrm{CH}_{3} \mathrm{SOOH}$ & 45 & 76 \\
\hline TTP & $4-\mathrm{CH}_{3} \mathrm{C}_{6} \mathrm{H}_{6} \mathrm{SOOH}$ & 4 & 41 & $4-\mathrm{CH}_{3} \mathrm{C}_{6} \mathrm{H}_{6} \mathrm{SOOH}$ & 5 & 42 \\
\hline TTP & 4- $\mathrm{CH}_{3} \mathrm{C}_{6} \mathrm{H}_{6} \mathrm{SOOH}$ & 6 & 49 & $4-\mathrm{CH}_{3} \mathrm{C}_{6} \mathrm{H}_{6} \mathrm{SOOH}$ & 10 & 55 \\
\hline TTP & 4- $\mathrm{CH}_{3} \mathrm{C}_{6} \mathrm{H}_{6} \mathrm{SOOH}$ & 8 & 56 & 4- $\mathrm{CH}_{3} \mathrm{C}_{6} \mathrm{H}_{6} \mathrm{SOOH}$ & 15 & 68 \\
\hline TTP & $4-\mathrm{CH}_{3} \mathrm{C}_{6} \mathrm{H}_{6} \mathrm{SOOH}$ & 10 & 64 & $4-\mathrm{CH}_{3} \mathrm{C}_{6} \mathrm{H}_{6} \mathrm{SOOH}$ & 30 & 80 \\
\hline TTP & $4-\mathrm{CH}_{3} \mathrm{C}_{6} \mathrm{H}_{6} \mathrm{SOOH}$ & 12 & 71 & $4-\mathrm{CH}_{3} \mathrm{C}_{6} \mathrm{H}_{6} \mathrm{SOOH}$ & 45 & 74 \\
\hline TTP & $\mathrm{CF}_{3} \mathrm{COOH}$ & 4 & 32 & $\mathrm{CF}_{3} \mathrm{COOH}$ & 5 & 30 \\
\hline TTP & $\mathrm{CF}_{3} \mathrm{COOH}$ & 6 & 46 & $\mathrm{CF}_{3} \mathrm{COOH}$ & 10 & 48 \\
\hline TTP & $\mathrm{CF}_{3} \mathrm{COOH}$ & 8 & 66 & $\mathrm{CF}_{3} \mathrm{COOH}$ & 15 & 74 \\
\hline TTP & $\mathrm{CF}_{3} \mathrm{COOH}$ & 10 & 70 & $\mathrm{CF}_{3} \mathrm{COOH}$ & 30 & 93 \\
\hline TTP & $\mathrm{CF}_{3} \mathrm{COOH}$ & 12 & 82 & $\mathrm{CF}_{3} \mathrm{COOH}$ & 45 & 90 \\
\hline TTQ & $\mathrm{CH}_{3} \mathrm{COOH}$ & 4 & 31 & $\mathrm{CH}_{3} \mathrm{COOH}$ & 5 & 30 \\
\hline TTQ & $\mathrm{CH}_{3} \mathrm{COOH}$ & 6 & 38 & $\mathrm{CH}_{3} \mathrm{COOH}$ & 10 & 42 \\
\hline TTQ & $\mathrm{CH}_{3} \mathrm{COOH}$ & 8 & 46 & $\mathrm{CH}_{3} \mathrm{COOH}$ & 15 & 50 \\
\hline TTQ & $\mathrm{CH}_{3} \mathrm{COOH}$ & 10 & 52 & $\mathrm{CH}_{3} \mathrm{COOH}$ & 30 & 56 \\
\hline TTQ & $\mathrm{CH}_{3} \mathrm{COOH}$ & 12 & 59 & $\mathrm{CH}_{3} \mathrm{COOH}$ & 45 & 54 \\
\hline TTQ & $\mathrm{CH}_{3} \mathrm{SOOH}$ & 4 & 36 & $\mathrm{CH}_{3} \mathrm{SOOH}$ & 5 & 44 \\
\hline TTQ & $\mathrm{CH}_{3} \mathrm{SOOH}$ & 6 & 43 & $\mathrm{CH}_{3} \mathrm{SOOH}$ & 10 & 52 \\
\hline TTQ & $\mathrm{CH}_{3} \mathrm{SOOH}$ & 8 & 54 & $\mathrm{CH}_{3} \mathrm{SOOH}$ & 15 & 63 \\
\hline TTQ & $\mathrm{CH}_{3} \mathrm{SOOH}$ & 10 & 60 & $\mathrm{CH}_{3} \mathrm{SOOH}$ & 30 & 70 \\
\hline TTQ & $\mathrm{CH}_{3} \mathrm{SOOH}$ & 12 & 64 & $\mathrm{CH}_{3} \mathrm{SOOH}$ & 45 & 68 \\
\hline TTQ & $4-\mathrm{CH}_{3} \mathrm{C}_{6} \mathrm{H}_{6} \mathrm{SOOH}$ & 4 & 40 & 4- $\mathrm{CH}_{3} \mathrm{C}_{6} \mathrm{H}_{6} \mathrm{SOOH}$ & 5 & 38 \\
\hline TTQ & 4- $\mathrm{CH}_{3} \mathrm{C}_{6} \mathrm{H}_{6} \mathrm{SOOH}$ & 6 & 52 & 4- $\mathrm{CH}_{3} \mathrm{C}_{6} \mathrm{H}_{6} \mathrm{SOOH}$ & 10 & 46 \\
\hline TTQ & $4-\mathrm{CH}_{3} \mathrm{C}_{6} \mathrm{H}_{6} \mathrm{SOOH}$ & 8 & 58 & $4-\mathrm{CH}_{3} \mathrm{C}_{6} \mathrm{H}_{6} \mathrm{SOOH}$ & 15 & 57 \\
\hline TTQ & $4-\mathrm{CH}_{3} \mathrm{C}_{6} \mathrm{H}_{6} \mathrm{SOOH}$ & 10 & 66 & $4-\mathrm{CH}_{3} \mathrm{C}_{6} \mathrm{H}_{6} \mathrm{SOOH}$ & 30 & 69 \\
\hline TTQ & $4-\mathrm{CH}_{3} \mathrm{C}_{6} \mathrm{H}_{6} \mathrm{SOOH}$ & 12 & 70 & $4-\mathrm{CH}_{3} \mathrm{C}_{6} \mathrm{H}_{6} \mathrm{SOOH}$ & 45 & 67 \\
\hline TTQ & $\mathrm{CF}_{3} \mathrm{COOH}$ & 4 & 36 & $\mathrm{CF}_{3} \mathrm{COOH}$ & 5 & 33 \\
\hline TTQ & $\mathrm{CF}_{3} \mathrm{COOH}$ & 6 & 44 & $\mathrm{CF}_{3} \mathrm{COOH}$ & 10 & 47 \\
\hline TTQ & $\mathrm{CF}_{3} \mathrm{COOH}$ & 8 & 57 & $\mathrm{CF}_{3} \mathrm{COOH}$ & 15 & 65 \\
\hline TTQ & $\mathrm{CF}_{3} \mathrm{COOH}$ & 10 & 65 & $\mathrm{CF}_{3} \mathrm{COOH}$ & 30 & 84 \\
\hline TTQ & $\mathrm{CF}_{3} \mathrm{COOH}$ & 12 & 74 & $\mathrm{CF}_{3} \mathrm{COOH}$ & 45 & 79 \\
\hline
\end{tabular}

*Klasik hidrodimerleşme reaksiyonları $50^{\circ} \mathrm{C}$ sıcaklıkta çinko tozu varlığında ultrases dalgaları olmadan gerçekleştirilmiştir. 

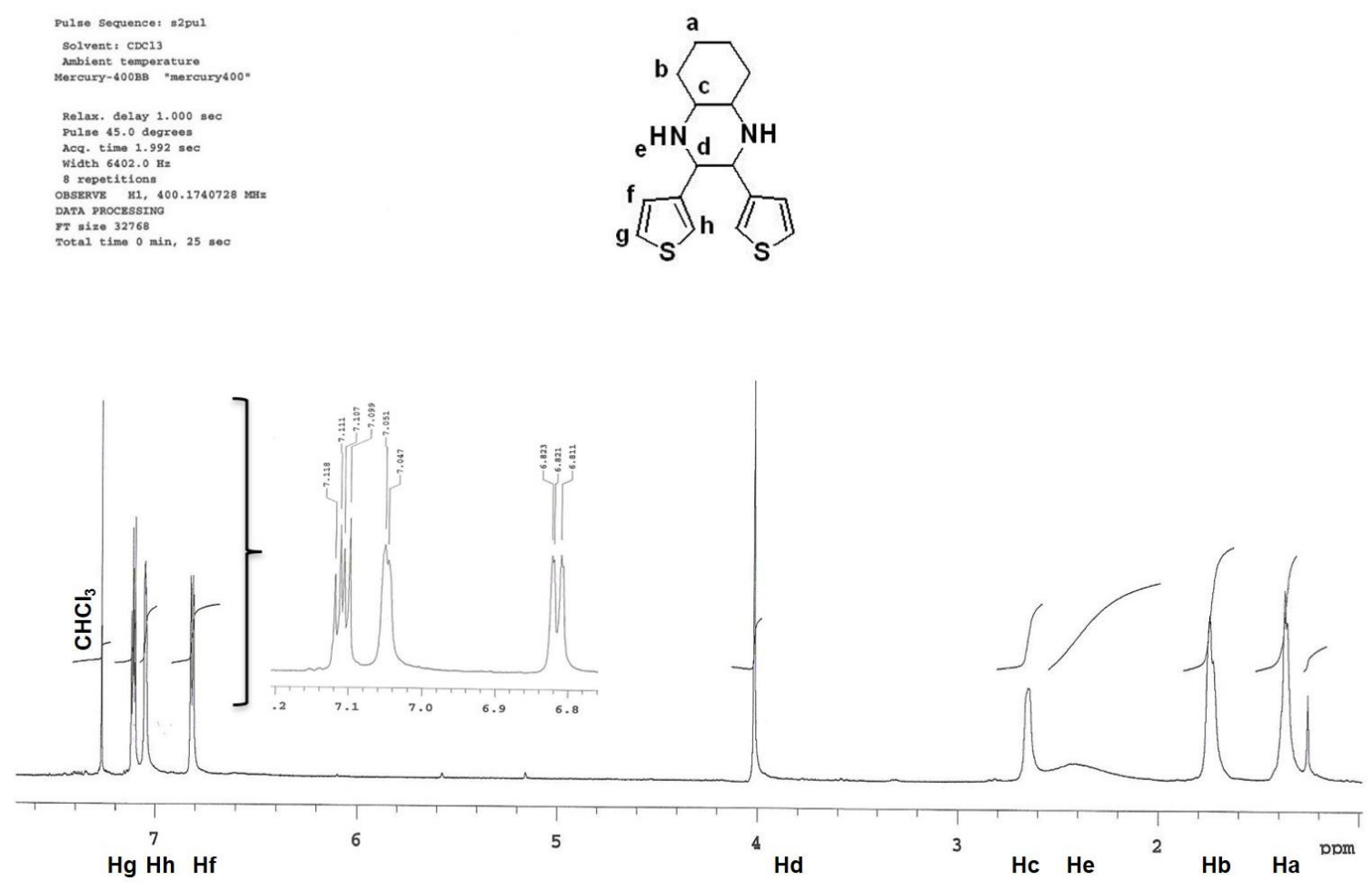

(a)
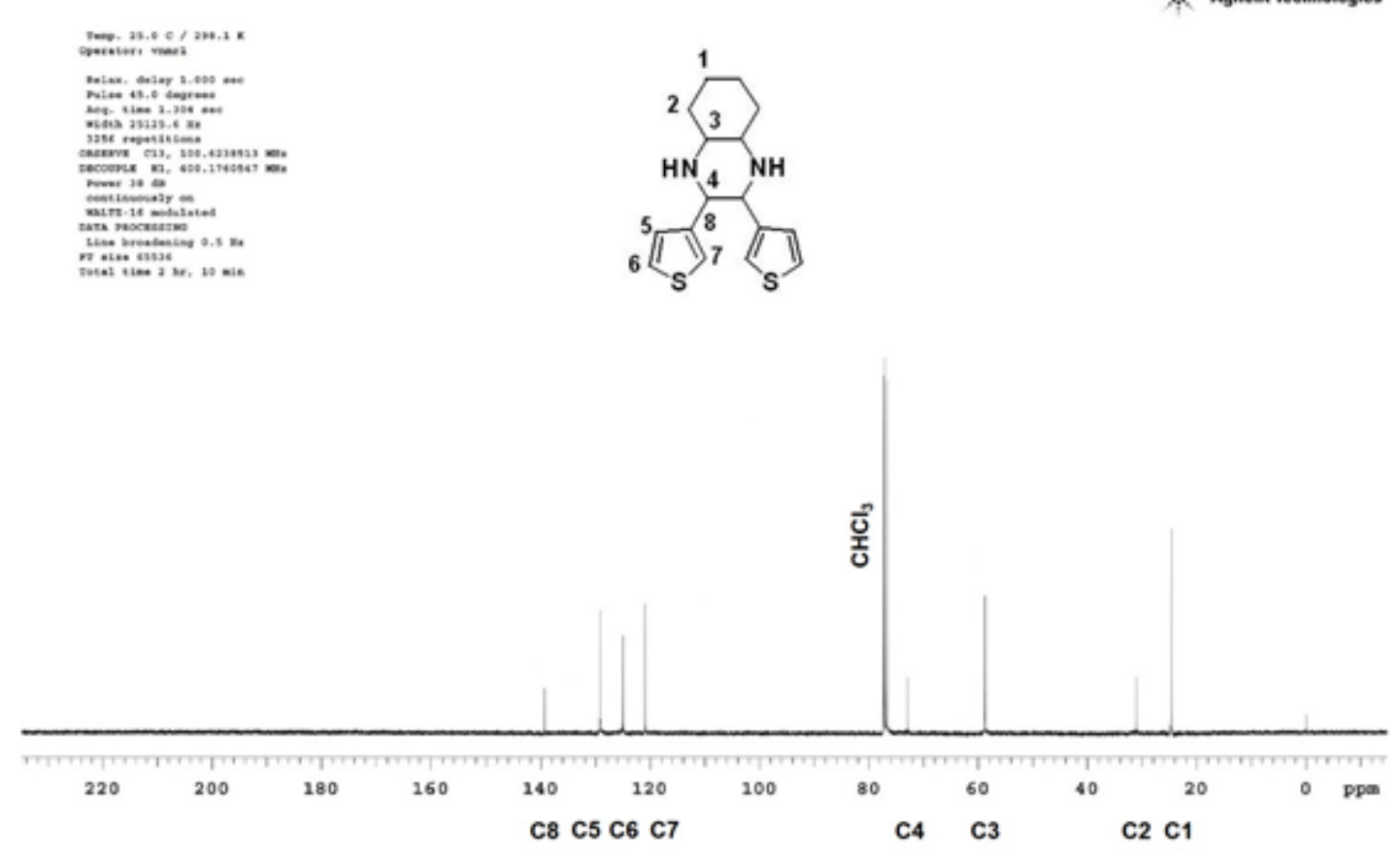

(b)

Şekil 2. (a) TTQ monomerinin ${ }^{1} H$ NMR spektrumu ve (b) TTQ monomerinin ${ }^{13}$ C NMR spektrumu

TTP ve TTQ monomerlerinin elektrokimyasal redoks davranışları dönüşümlü voltametri tekniği ile incelenmiştir. $100 \mathrm{mVs}^{-1}$ tarama hızı kullanılarak $0-2,0 \mathrm{~V}$ potansiyel aralığında kaydedilen dönüşümlü voltamogramlar Şekil 3'de gösterilmiştir. Dönüşümlü voltamogramlarda görüleceği üzere, TTP ve TTQ 
monomerleri sırasıyla $1,72 \mathrm{~V}$ ve $1,77 \mathrm{~V}$ potansiyel değerlerinde tersinmez yükseltgenme davranışları sergilemiştir (Şekil 3 (a) ve (b)). Monomer yükseltgenmelerinin ardından, her yükseltgenme/indirgenme döngüsü ile birlikte akım yoğunluğu değerlerinde düzgün bir artış gözlenmiştir. Bu durum platin disk çalışma elektrotlarının yüzeylerinde polimerik filmlerin meydana geldiğini ve bu filmlerin iletken özelliğe sahip olduğunu ortaya koymaktadır. İletken polimer filmlerin redoks özellikleri, monomer içermeyen destek elektroliti çözeltisinde PTTP ve PTTQ kaplanmış platin disk elektrotlar kullanılarak gerçekleştirilen tek tarama dönüşümlü voltametri çalışmaları ile incelenmiştir. Anodik bölgede yapılan potansiyel taramalarında PTTP ve PTTQ için tersinir redoks pikleri gözlenmiştir (Şekil 3 (c) ve (d)). İletken polimerler için karakteristik olan bu elektrokimyasal redoks davranışı PTTP ve PTTQ iletken polimer filmlerin pozitif katkılanabilme (p-doping) özelliğine sahip olduğunu anlamına gelmektedir. Diğer taraftan, negatif potansiyel bölgesinde yapılan taramalarda her iki iletken polimer türevi için benzer bir redoks davranışı (negatif katkılanma, n-doping) tespit edilememiştir. TTP ve TTQ monomerlerine ait elektropolimerizasyon mekanizması Şekil 4'te yer almaktadır.
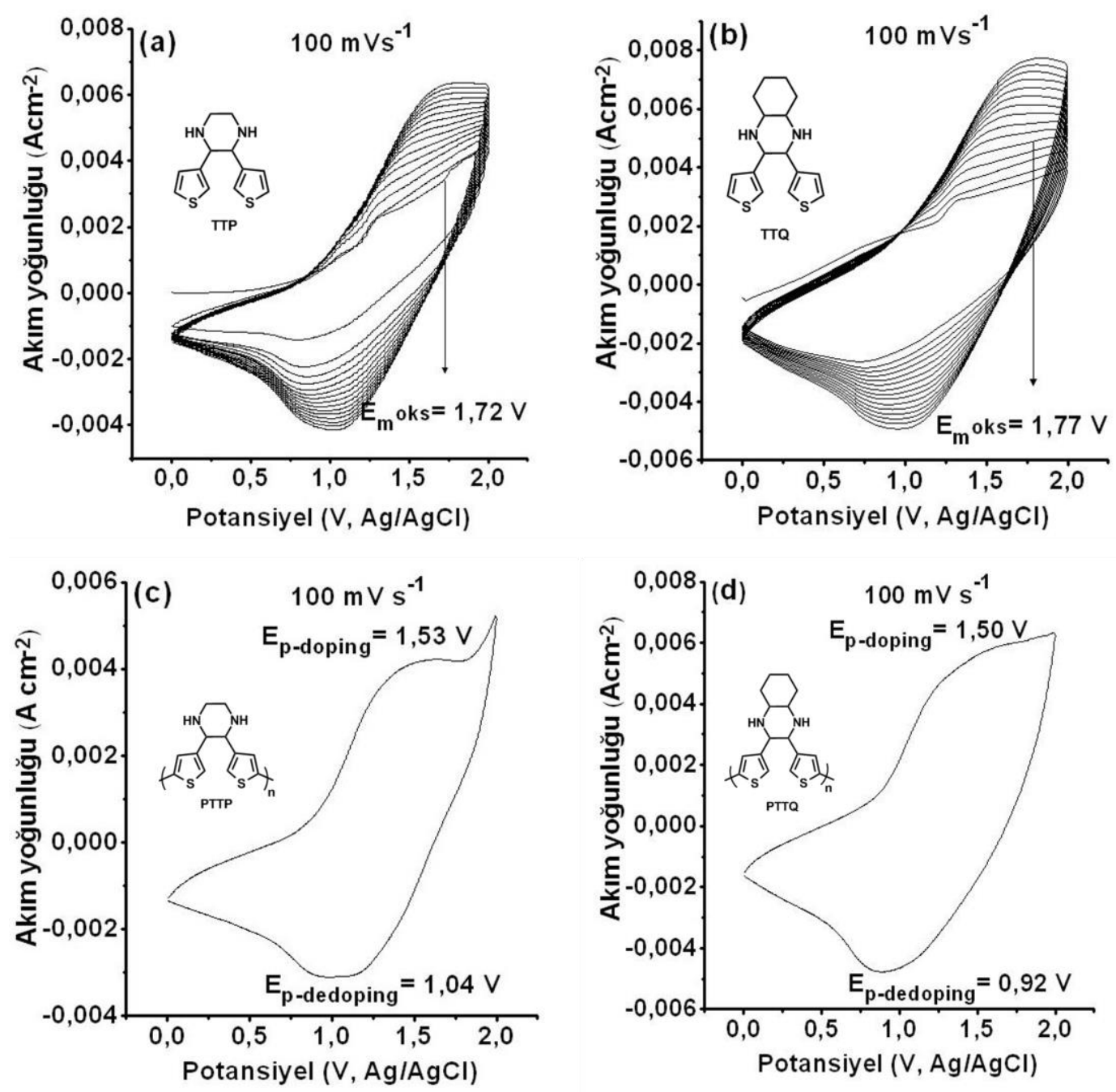

Şekil 3. (a) TTP monomerinin dönüşümlü voltamogramı (b) TTQ monomerinin dönüşümlü voltamogramı (c) PTTP iletken polimer filminin tek taramalı dönüşümlü voltamogramı ve (d) PTTQ iletken polimer filminin tek taramalı dönüşümlü voltamogramı monomerinin dönüşümlü voltamogramı 


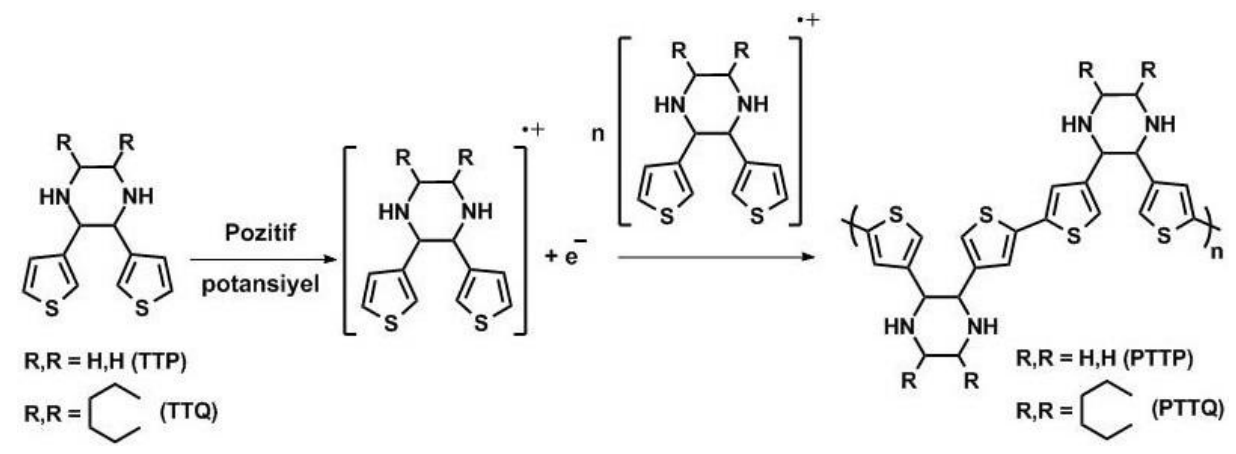

Şekil 4. TTP ve TTQ monomerlerinin elektrokimyasal polimerizasyon reaksiyon mekanizması

İletken polimer türevlerinin tersinir redoks özelliklerinin yanı sıra, tarama hızına karşı anodik ve katodik pik akım yoğunluğu değerlerindeki değişimler de incelenmiştir. $\mathrm{Bu}$ amaçla, platin disk elektrot yüzeylerine kaplanmış olan PTTP ve PTTQ iletken polimer filmlere $50 \mathrm{mV} \mathrm{s}^{-1}$ ' den $500 \mathrm{mVs}^{-1}$ ' ye kadar farklı tarama hızları uygulanmıştır. Şekil 5'te gösterildiği gibi, PTTP ve PTTQ iletken polimerlerin anodik ve katodik pik akım yoğunlukları tarama hızının bir fonksiyonu olarak doğrusal bir değişim göstermiştir. Bu çalışmalardan elde edilen sonuçlar, iletken polimer filmler ile metal elektrot yüzeyleri arasında güçlü etkileşimler kurulduğunu ve PTTP ve PTTQ' de meydana gelen redoks süreçlerinin difüzyon kontrollü olmadığı ortaya koymaktadır.
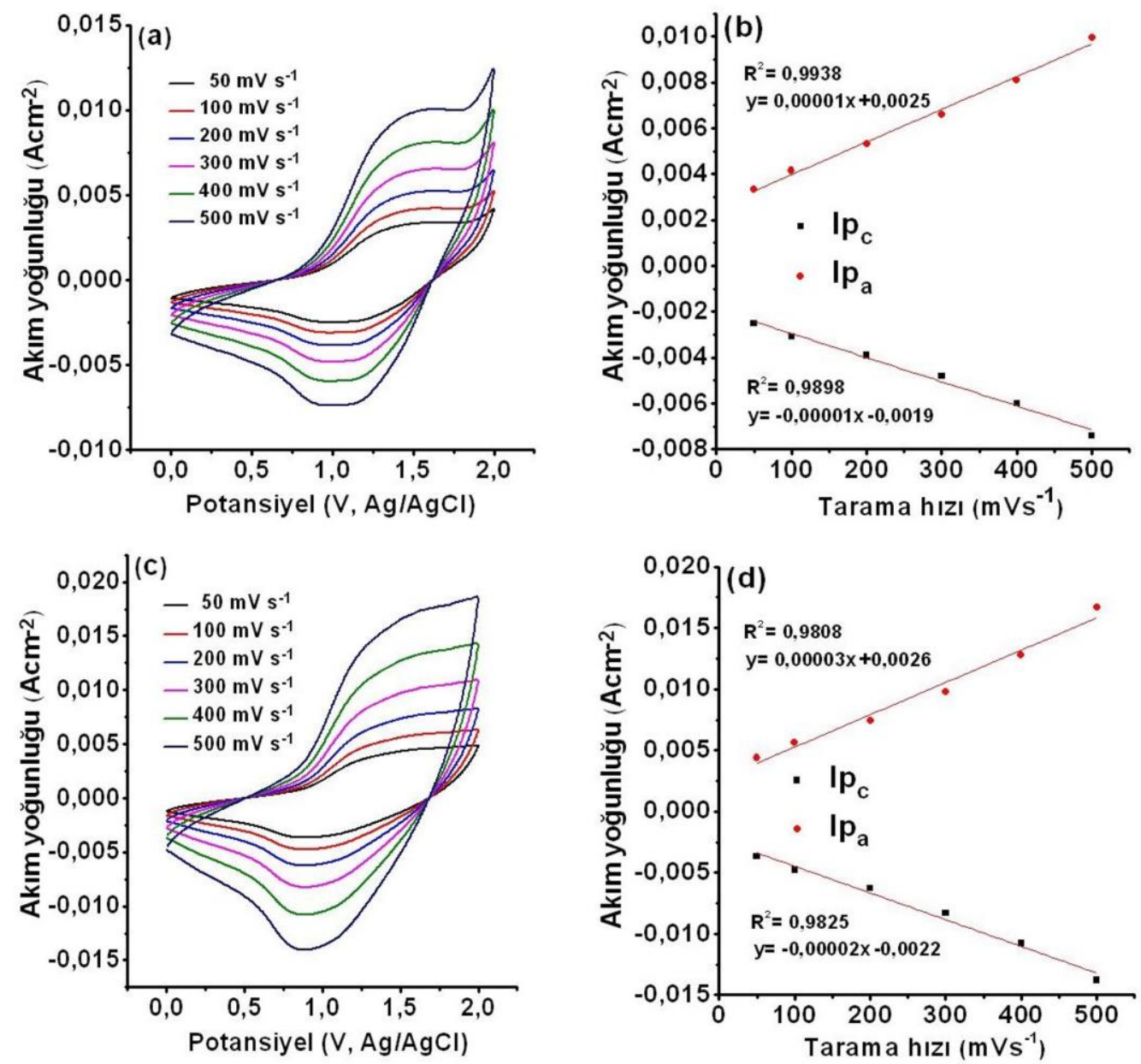

Şekil 5. (a) PTTP iletken polimer filminin farklı tarama hızlarındaki dönüşümlü voltamogramları (b) PTTP' ye ait tarama hızına karşı pik akım yoğunluğu değişim grafiği (c) PTTQ iletken polimer filminin farklı tarama hızlarındaki dönüşümlü voltamogramları (d) PTTQ' ya ait tarama hızına karşı pik akım yoğunluğu değişim grafiği 
Monomerlerin ve iletken polimerlerin elektrokimyasal davranışlarının karakterize edilmesinden sonra, PTTP ve PTTQ kaplı paslanmaz çelik redoks elektrot malzemeleri hazırlanmıştır. Paslanmaz çelik levhalar üzerinde biriktirilen iletken polimer film kütlelerinin hassas bir biçimde kontrol edilebilmesi ve homojen bir kaplama sağlanabilmesi amacıyla, elektrot malzemelerinin hazırlanması için sabit potansiyel elektroliz tekniği tercih edilmiştir. Monomer yükseltgenme potansiyellerinde gerçekleştirilen sabit potansiyel elektroliz çalışmaları ile paslanmaz çelik substratlar $0,15 \mathrm{mgcm}^{-2}$ PTTP ve $0,18 \mathrm{mgcm}^{-}$ ${ }^{2}$ PTTQ esaslı elektroaktif maddeler ile kaplanmıştır. PTTP ve PTTQ iletken polimer yüzeylerin kimyasal karakterizasyonu FTIR spektroskopi ile gerçekleştirilirken, morfolojik özellikleri ise SEM teknikleri kullanılarak incelenmiştir. Şekil 6' daki SEM fotoğrafları PTTP ve PTTQ iletken polimer filmlerin paslanmaz çelik substratların yüzeyine düzgün ve homojen bir biçimde kaplandığını göstermektedir. Ayrıca, SEM analizleri PTTP ve PTTQ polimerik yüzeylerin iyon hareketliliğini kolaylaştırabilecek nitelikteki gözenekli bir yapıya sahip olduğunu da ortaya koymaktadır.
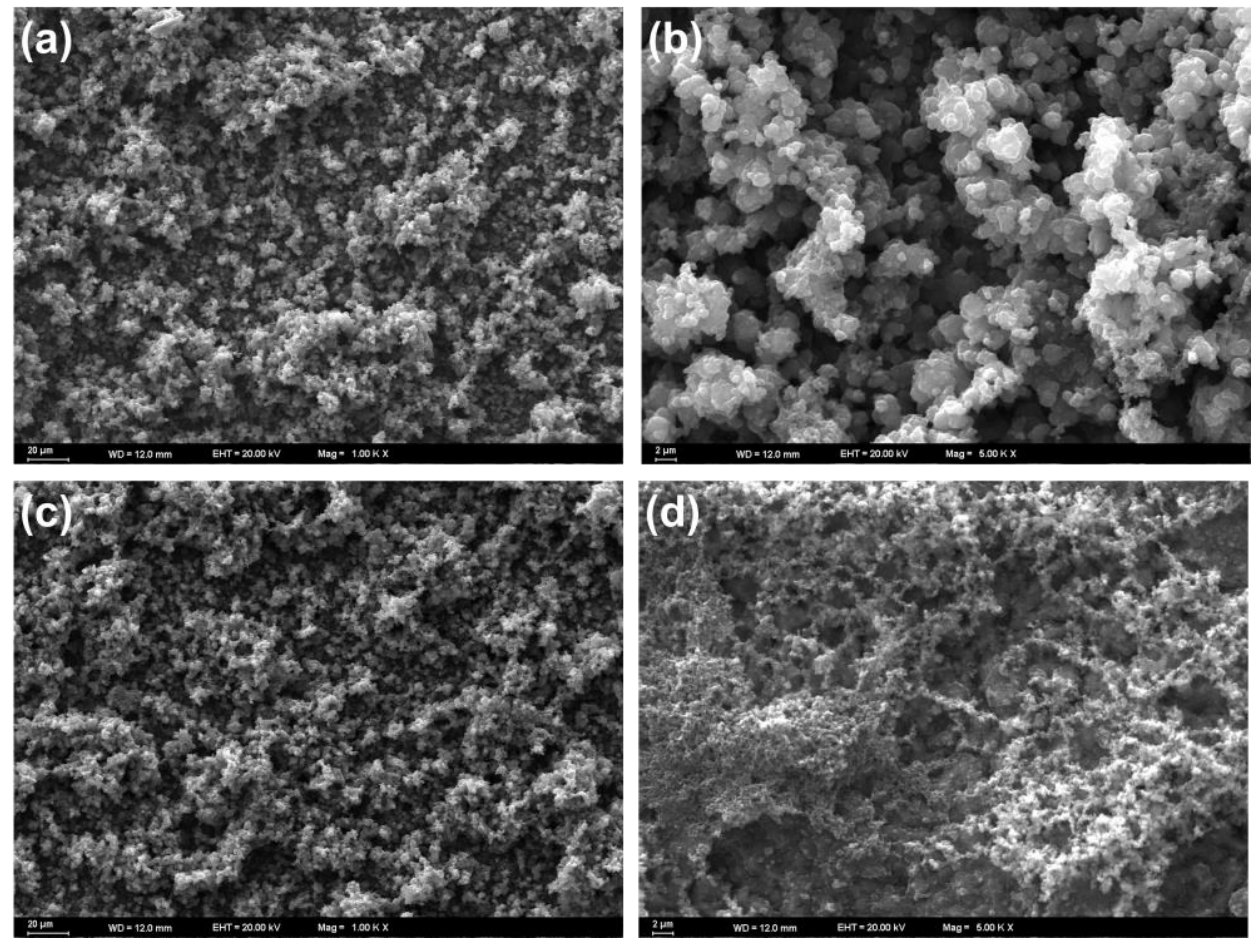

Şekil 6. (a) PTTP iletken polimer filminin 1 KX büyütme oranındaki (b) PTTP iletken polimer filminin 5 KX büyütme oranındaki (c) PTTQ iletken polimer filminin $1 \mathrm{KX}$ büyütme oranındaki (d) PTTQ iletken polimer filminin 5 KX büyütme oranindaki SEM görüntüleri

Hazırlanan PTTP ve PTTQ esaslı redoks aktif malzemelerinin süperkapasitör özellikleri CV, GCD ve EIS teknikleriyle araştırılmıştır. Kapasitif performans değerlendirmeleri için daha kesin sonuçların elde edilmesine olanak sağlayan iki elektrot konfigürasyonuna sahip bir test hücresi kullanılmıştır. İlk olarak, polimerik redoks aktif elektrot malzemelerinin $0-1,85 \mathrm{~V}$ potansiyel aralığında farklı tarama hızlarında dönüşümlü voltamogramları kaydedilmiştir. CV çalışmalarında, PTTP ve PTTQ elektrotlar, iletken polimer esaslı kapasitif malzemeler için karakteristik olan mekik benzeri akım-potansiyel profilleri ortaya koymuşlardır (Şekil 7). Bu akım-potansiyel profilleri, şarj-deşarj süreçleri sırasında PTTP ve PTTQ elektrotlarında yoğun redoks proseslerinin meydana geldiğini göstermektedir. Diğer taraftan, artan tarama hızlarına $\left(10 \mathrm{mVs}^{-1} \rightarrow 250 \mathrm{mVs}^{-1}\right)$ karşı PTTP ve PTTQ redoks aktif elektrot malzemelerinin akım-potansiyel profillerinde herhangi bir şekil değişikliği oluşmamıştır. Bu gözlem, çalışma kapsamında hazırlanan yeni PTTP ve PTTQ elektrot malzemelerinin çok hızlı ve tersinir bir redoks özelliğine sahip olduğunu doğrulamaktadır. 

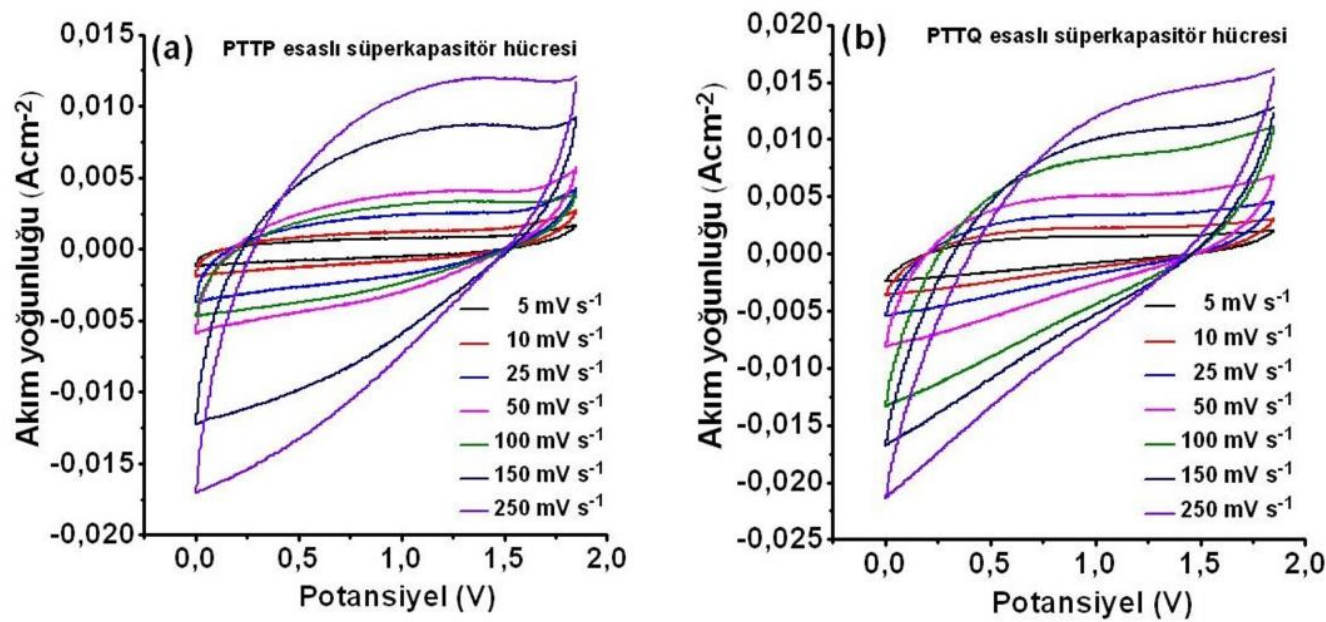

Şekil 7. (a) PTTP esasl süperkapasitör hücresinin ve (b) PTTQ esaslı süperkapasitör hücresinin farklı tarama hızlarındaki $\left(5-250 \mathrm{mVs}^{-1}\right)$ dönüşümlü voltamogramları

PTTP ve PTTQ redoks aktif elektrot malzemelerinin sabit akım altındaki şarj-deşarj davranışları ise GCD çalışmaları ile test edilmiştir. Şekil 8 (a) ve (b)' de görüleceği üzere, PTTP ve PTTQ elektrot malzemeleri $2,5 \mathrm{mAcm}^{-2}$ sabit akım yoğunluğunda oldukça düşük IR (ohmic drop) değerlerine sahip simetrik şekle yakın GCD eğrileri oluşturmuşlardır. $\mathrm{Bu}$ profil şekilleri polimerik elektrot malzemelerinin düşük iç dirençlere sahip olduğunu ve bu sayede dengeli bir şarj-deşarj döngüsü sergileyebildiklerini göstermektedir.
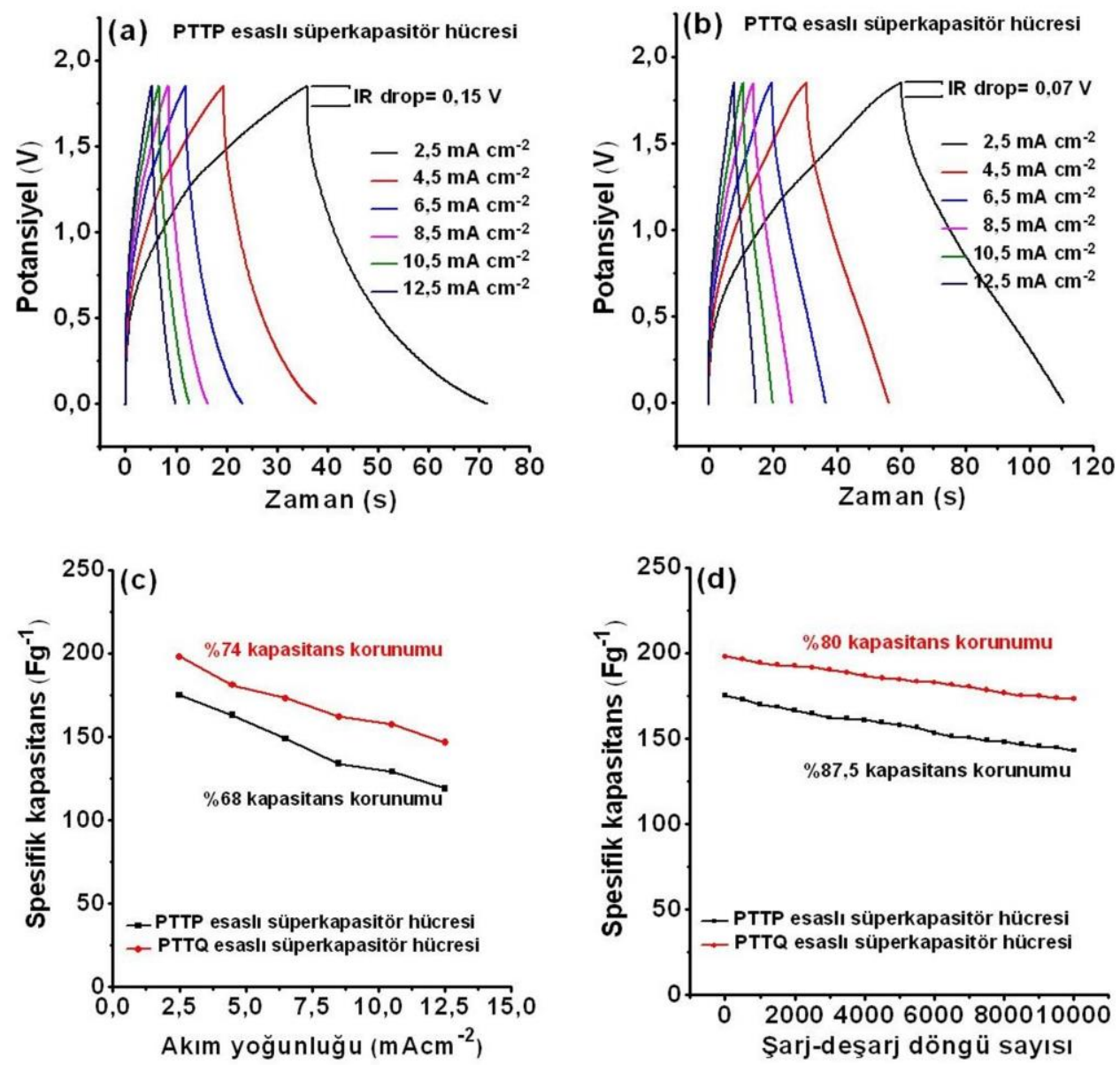

Şekil 8. (a) PTTP esaslı süperkapasitör hücresinin farklı akım yoğunluklarındaki GCD ĕgrileri (b) PTTQ esash süperkapasitör hücresinin farklı akım yoğunluklarındaki GCD eğrileri (c) PTTP ve PTTQ esaslı süperkapasitör hücrelerinin artan akım yoğunluklarına karşı spesifik kapasitans değişimleri (d) PTTP ve PTTQ esaslı süperkapasitör hücrelerinin uzun şarj-deşarj döngü ömürleri (10 000 döngü) 
$2,5 \mathrm{mAcm}^{-2}$ sabit akım yoğunluğunda kaydedilen GCD eğrileri kullanılarak PTTP ve PTTQ redoks aktif elektrot malzemelerinin spesifik kapasitans $\left(\mathrm{C}_{\mathrm{spec}}\right)$, enerji (SE) ve güç yoğunluğu (SP) değerleri eşitlik (1), (2) ve (3) uyarınca hesaplanmış ve Tablo 3'de gösterilmiştir. Elde edilen sonuçlar PTTQ esaslı redoks aktif elektrot malzemesinin $\left(\mathrm{C}_{\text {spec }}=198 \mathrm{Fg}^{-1}\right)$ PTTP' ye göre $\left(\mathrm{C}_{\text {spec }}=175 \mathrm{Fg}^{-1}\right)$ daha iyi bir yük depolama performans sergilediğini ortaya koymaktadır. Elektrot malzemelerinin birbirlerine çok yakın elektroaktif madde miktarları içerdiği göz önüne alındığında, PTTQ’ nin üstün kapasitif performansının doğrudan morfolojik özellikleri ile ilişkilendirilmesi mümkündür. PTTP polimerik filmlere kıyasla, PTTQ' nin morfolojik yapısının şarj-deşarj süreçlerinde daha fazla elektrolit iyonunun depolanabilmesine olanak sağlayan gözenekli bir karaktere sahip olduğu söylenebilir. Diğer taraftan, PTTP ve PTTQ polimerik redoks aktif elektrot malzemelerinin sahip olduğu bu kapasitif performans değerleri literatürde yer alan ve farklı kimyasal yapılara sahip politiyofen türevlerinin kapasitif özellikleri ile kıyaslanabilir düzeydedir (Tablo 4).

Tablo 3. PTTP ve PTTQ redoks aktif elektrot malzemelerinin kapasitif performans değerleri

\begin{tabular}{cccc}
\hline Elektrot malzemesi & $\begin{array}{c}\text { Spesifik kapasitans } \\
\left(\boldsymbol{C}_{\text {spec }}, \boldsymbol{F g}^{-1}\right)\end{array}$ & $\begin{array}{c}\text { Enerji yŏ̆unlŭ̆u } \\
\left(\boldsymbol{S E}, \mathbf{W h k g}^{-1}\right)\end{array}$ & $\begin{array}{c}\text { Güç yoğunluğu (SP, } \\
\left.\mathbf{k W k g}^{-1}\right)\end{array}$ \\
\hline PTTP & 175 & 70,2 & 7 \\
\hline PTTQ & 198 & 87,1 & 6,2 \\
\hline
\end{tabular}

GCD analizleri ile PTTP ve PTTQ esaslı elektrot malzemelerinin redoks kapasiteleri ve uzun süreli şarjdeşarj döngü ömürleri de incelenmiştir. Redoks kapasitesi ve uzun süreli şarj-deşarj döngü kararlılığ1 pratik süperkapasitör uygulamaları açısından oldukça önemli kapasitif performans parametreleridir. İletken polimer esaslı elektrot malzemelerinden yüksek redoks reaksiyonu kapasitelerine ve oldukça uzun döngü ömrü kararlılıklarına sahip olmaları beklenmektedir. Bu doğrultuda, PTTP ve PTTQ redoks aktif elektrot malzemelerinin $2,5,4,5,6,5,10,5$ ve $12,5 \mathrm{mAcm}^{-2}$ akım yoğunluklarındaki GCD eğrileri kaydedilmiştir. Bu akım yoğunlukları kullanılarak yapılan spesifik kapasitans hesaplamaları PTTP (175 $\mathrm{Fg}^{-1}$ ' dan $119 \mathrm{Fg}^{-1}$ ' a düşüş) ve PTTQ (198 Fg ${ }^{-1}$, dan $146,5 \mathrm{Fg}^{-1}$ 'a düşüş $)$ elektrot malzemelerinin sırasıyla $\% 68$ ve \%74 kapasitans korunum değerlerine sahip olduğunu ortaya koymuştur (Şekil 8 (c)). Bu sonuçlar PTTP ve PTTQ elektrot malzemelerinin yüksek akım yoğunluğu değerlerinde bile oldukça iyi redoks reaksiyonu oranlarına sahip olduğunu göstermektedir. GCD analizlerinden elde edilen bu veriler CV çalışmalarından elde edilen verileri bütünüyle desteklemektedir. Diğer taraftan, PTTP ve PTTQ redoks aktif elektrot malzemeleri $2,5 \mathrm{mAcm}^{-2}$ sabit akım yoğunluğunda 10000 şarj-deşarj döngüsü için kaydedilen GCD testlerinde 10000 döngünün sonunda başlangıç spesifik kapasitans değerlerinin \%80 ve \%87,5'ni korumayı başarmıştır (Şekil 8 (d)). PTTP ve PTTQ iletken polimer filmlerin sergilemiş oldukları bu yüksek döngü kararlılıkları, şarj-deşarj işlemleri sırasında polimer yüzeylerinde meydana gelen şişme ve büzüşme hareketlerine dayalı olarak gözlenebilecek fiziksel deformansyonların kabul edilebilir düzeyde olduğu anlamına gelmektedir. 
Tablo 4. Politiyofen türevi farklı redoks aktif elektrot malzemelerinin kapasitif performans değerleri

\begin{tabular}{|c|c|c|c|c|}
\hline $\begin{array}{l}\text { Redoks aktif } \\
\text { malzeme }\end{array}$ & $\begin{array}{c}\text { Çalışma } \\
\text { potansiyel aralığı }\end{array}$ & $\begin{array}{c}\text { Elektrolitik ortam } \\
\text { koşulları }\end{array}$ & $\begin{array}{c}\text { Spesifik } \\
\text { kapasitans } \\
\left(\mathbf{C}_{\text {spec }}\right) \\
\end{array}$ & Referans \\
\hline & $-2 \mathrm{~V}-1 \mathrm{~V}$ & $\mathrm{Et}_{4} \mathrm{NCF}_{3} \mathrm{SO}_{3}$ /asetonitril & $45 \mathrm{Fg}^{-1}$ & 33 \\
\hline & $-0,2 \mathrm{~V}-1,9 \mathrm{~V}$ & $\mathrm{LiClO}_{4}$ /asetonitril & $212 \mathrm{Fg}^{-1}$ & 34 \\
\hline & $-0,2 \mathrm{~V}-1,0 \mathrm{~V}$ & $\mathrm{Et}_{4} \mathrm{NBF}_{4} /$ propilen karbonat & $110 \mathrm{Fg}^{-1}$ & 36 \\
\hline & $0,0 \mathrm{~V}-2,9 \mathrm{~V}$ & $\mathrm{Et}_{4} \mathrm{NBF}_{4}$ /asetonitril & $170 \mathrm{Fg}^{-1}$ & 37 \\
\hline & $0,0 \mathrm{~V}-3,0 \mathrm{~V}$ & $\begin{array}{l}\mathrm{LiPF}_{6} / \text { etilen } \\
\text { karbonat/dimetil karbonat }\end{array}$ & $56 \mathrm{Fg}^{-1}$ & 38 \\
\hline & $0,0 \mathrm{~V}-1,85 \mathrm{~V}$ & $\mathrm{LiClO}_{4}$ /asetonitril & $175 \mathrm{Fg}^{-1}$ & $\begin{array}{c}\mathrm{Bu} \\
\text { çalışma }\end{array}$ \\
\hline & $0,0 \mathrm{~V}-1,85 \mathrm{~V}$ & $\mathrm{LiClO}_{4}$ /asetonitril & $198 \mathrm{Fg}^{-1}$ & $\begin{array}{c}\mathrm{Bu} \\
\text { çalışma }\end{array}$ \\
\hline
\end{tabular}

PTTP ve PTTQ redoks aktif elektrot malzemelerinin kapasitif özelliklerinin incelenmesine yönelik çalışmaların son aşamasında ise EIS analizleri gerçekleştirilmiştir. EIS sonuçlarından yararlanarak PTTP ve PTTQ elektrot malzemeleri için eşdeğer seri direnç (equivalent series resistance, ESR) ve yük transfer direnci (charge transfer resistance, $\mathrm{R}_{\mathrm{CT}}$ ) gibi süperkapasitör uygulamaları açısından oldukça önemli olan elektronik değerler belirlenmiştir. Şekil 9' da görüleceği üzere, PTTP ve PTTQ elektrot malzemeleri yüksek frekans bölgesinde bir yarım daire, düşük frekans bölgesinde ise bir lineer bileşenden oluşan için Nyquist eğri desenleri sergilemiştir. Bu impedans deseni iletken polimer esaslı kapasitif elektroaktif malzemeler için karakteristik bir davranış olup, PTTP ve PTTQ elektrot malzemelerinin ideal süperkapasitör özellikleri sergilediğini göstermektedir. Diğer taraftan, Nyquist eğrilerinin yüksek frekans bölgelerinden elde edilen veriler PTTP ve PTTQ redoks aktif elektrot malzemelerinin düşük ESR (PTTP için $\mathrm{ESR}=3,07 \Omega$ ve PTTQ için $\mathrm{ESR}=3,05 \Omega$ ) ve $\mathrm{R}_{\mathrm{CT}}(\mathrm{PTTP}$ için $\mathrm{R}_{\mathrm{CT}}=12,8 \Omega$ ve PTTQ için $\mathrm{R}_{\mathrm{CT}}=9,97 \Omega$ ) değerlerine sahip olduğunu ortaya koymuştur. Bu düşük ESR ve $\mathrm{R}_{\mathrm{CT}}$ değerleri PTTP ve PTTQ iletken polimer filmlerin, kolay iyon hareketliliğine ve hızlı yük transfer süreçlerine olanak sağlayabilen uygun üç boyutlu morfolojik yapılara sahip olduğunu ifade etmektedir.

İmpedans temelli deneysel çalışmalarının yanı sıra, Nyquist eğrilerinden elde edilen veriler doğrultusunda PTTP ve PTTQ esaslı simetrik süperkapasitör hücrelerine ait teorik eşdeğer devre modellemeleri de oluşturulmuştur. $\mathrm{Bu}$ eşdeğer devre modellemelerinde iletken polimer film 
yüzeylerinde meydana gelen Faradayik süreçlerden kaynaklanan pseudokapasitans eşdeğer devre elemanlarının yer alması deneysel verilerden elde edilen sonuçları desteklemektedir.
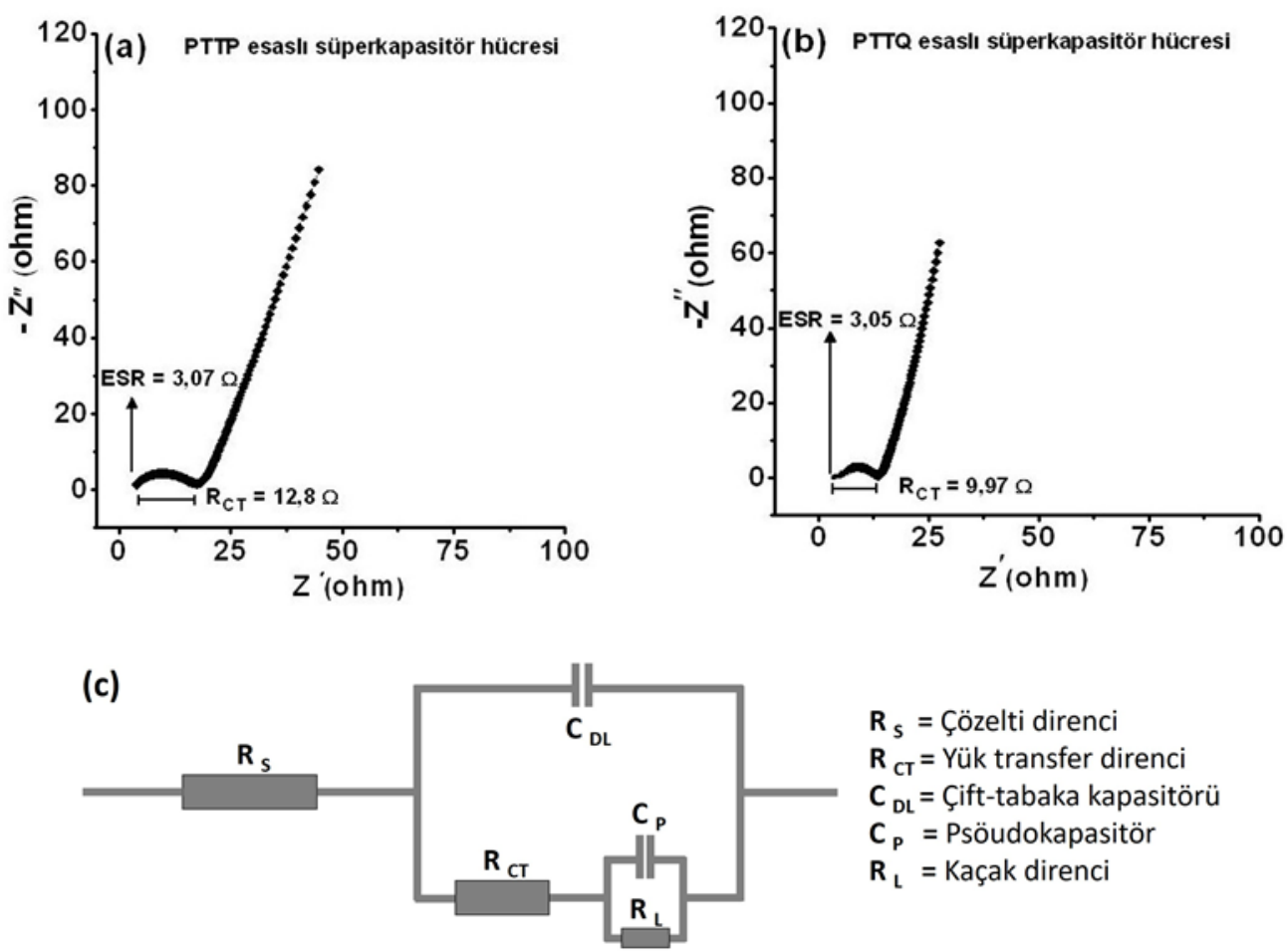

$\mathbf{R}_{\mathrm{S}}=$ Çözelti direnci

$\mathbf{R}_{\mathrm{CT}}=$ Yük transfer direnci

$\mathrm{C}_{\mathrm{DL}}=$ Çift-tabaka kapasitörü

$\mathrm{C}_{\mathrm{p}}=$ Psöudokapasitör

$\mathbf{R}_{\mathrm{L}}=$ Kaçak direnci

Şekil 9. (a) PTTP esasl süperkapasitör hücresinin (b) PTTQ esasll süperkapasitör hücresinin Nyquist impedans eğrileri $(10 \mathrm{kHz}-0,01 \mathrm{~Hz})$ ve (c) PTTP ve PTTQ esasl simetrik süperkapasitör hücrelerine ait eşdeğer elektronik devre modeli ve devre elemanlart

\section{IV.SONUC}

$\mathrm{Bu}$ çalışma kapsamında, 2,3-di(tiyofen-3-il)piperazin yapısına sahip yeni elektroaktif monomer türevlerinin (TTP ve TTQ) sentezi gerçekleştirilmiş, elektropolimerizasyon tekniği ile iletken polimerleri (PTTP ve PTTQ) hazırlanmış ve iletken polimer esaslı malzemelerin süperkapasitör özellikleri detaylı olarak incelenmiştir. Paslanmaz çelik akım toplayıcı substratlar üzerinde polimerleştirilen PTTP ve PTTQ iletken polimer filmlerin kapasitif performansları CV, GCD ve EIS teknikleri yardımıyla iki elektrot konfigürasyonuna sahip bir hücre kullanılarak test edilmiştir. PTTP ve PTTQ esaslı redoks aktif elektrot malzemeleri $0-1,85 \mathrm{~V}$ potansiyel aralığında oldukça tatmin edici yük depolama kapasiteleri $\left(\mathrm{C}_{\text {spec }}=175 \mathrm{Fg}^{-1}\right.$ ve $\left.\mathrm{C}_{\text {spec }}=198 \mathrm{Fg}^{-1}\right)$, enerji yoğunluğu $\left(\mathrm{SE}=70,2 \mathrm{Whkg}^{-1}\right.$ ve $\mathrm{SE}=$ $\left.87,1 \mathrm{Whkg}^{-1}\right)$ ve güç yoğunluğu $\left(\mathrm{SP}=7 \mathrm{kWkg}^{-1}\right.$ ve $\left.\mathrm{SP}=6,2 \mathrm{kWkg}^{-1}\right)$ değerlerine ulaşmıştır. Daha da önemlisi, PTTP ve PTTQ redoks aktif elektrotları $2,5 \mathrm{mAcm}^{-2}$ sabit akım yoğunluğu altında 10000 şarjdeşarj döngüsü için yüksek döngü kararlılıkları (\%80 ve \%87,5 kapasitans korunum değerleri) sergilemiştir. Elde edilen bu kapasitif performans değerleri, literatürde yer alan farklı kimyasal yapılara sahip tiyofen esaslı iletken polimer türevlerinin kapasitif performansları ile kıyaslanabilir düzeydedir [33-38]. Ayrica, elektrokimyasal performans testleri PTTP ve PTTQ iletken polimer filmlerin iyon hareketlerini kolaylaştıran ve hızlı yük transfer süreçlerine olanak sağlayan uygun morfolojik özelliklere sahip olduğunu da ortaya koymuştur. Bu bağlamda, PTTP ve PTTQ esaslı polimerik yapılar, bu tür elektrokimyasal ve morfolojik özellikleri sergilemiş olmaları bakımından, yüksek performanslı enerji depolama sistemlerinde kullanılabilme potansiyeline sahip uygun redoks aktif elektrot malzemeleri olarak değerlendirilmektedir. Sonuç olarak, bu çalışma ile farklı kimyasal yapılardaki yeni iletken polimer türevlerinin sentezlenmesinin üstün kapasitif performanslar sergileyebilecek redoks aktif elektrot malzemelerinin hazırlanmasında etkin bir yöntem olarak kullanılabileceği gösterilmiştir. 
TEȘEKKÜR: Yazar, Türkiye Bilimsel ve Teknolojik Araştırmalar Kurumu'na (TÜBİTAK) KBAG$114 Z 167$ nolu proje kapsamında sağlamış olduğu doktora sonrası araştırmacı bursu için teşekkür eder. Ayrıca, yazar, Prof. Dr. Mustafa GÜLLÜ’ ye (Ankara Üniversitesi, Fen Fakültesi, Kimya Bölümü) araştırma için sunmuş olduğu imkanlardan dolayı teşekkür eder.

\section{KAYNAKLAR}

[1] D. Yiğit, Ş.O. Hacioğlu, M. Güllü, L. Toppare, "Novel poly(2,5-dithienylpyrrole) (PSNS) derivatives functionalized with azobenzene, coumarin and fluorescein chromophore units: spectroelectrochemical properties and electrochromic device applications," New Journal of Chemistry, vol. 39, no. 5, pp 3371-3379, 2015.

[2] A. Chaudhary, D.K. Pathak, M. Tanwar, P. Yogi, P.R. Sagdeo, R. Kumar, "Polythiophene-PCBMbased all-organic electrochromic device: fast and flexible," ACS Applied Electronic Materials, vol. 1, no.1, pp. 58-63, 2019.

[3] M. Caliskan, M.C. Erer, S.T. Aslan, Y.A. Udum, L. Toppare, A. Cirpan, "Narrow band gap benzodithiophene and quinoxaline bearing conjugated polymers for organic photovoltaic applications," Dyes and Pigments, vol. 180, pp. 108479, 2020.

[4] T.M. Clarke, A.M. Ballantyne, J. Nelson, D.D. Bradley, J.R. Durrant, (2008), "Free energy control of charge photogeneration in polythiophene/fullerene solar cells: the influence of thermal annealing on P3HT/PCBM blends," Advanced Functional Materials, vol. 18, no. 24, pp. 4029-4035, 2008.

[5] C. Kok, C. Doyranli, B. Canımkurbey, S.P. Mucur, S. Koyuncu, "Effect of thiophene linker addition to fluorene-benzotriazole polymers with the purpose of achieving white emission in OLEDs," $R S C$ Advances, vol. 10, no. 32, pp. 18639-18647, 2020.

[6] J. Ohshita, Y. Tada, A. Kunai, Y. Harima, Y. Kunugi, "Hole-injection properties of annealed polythiophene films to replace PEDOT-PSS in multilayered OLED systems," Synthetic Metals, vol. 159, no. 3-4, pp. 214-217, 2009.

[7] B. Li, D.N. Lambeth, "Chemical sensing using nanostructured polythiophene transistors," Nano Letters, vol. 8, no. 11, pp. 3563-3567, 2008.

[8] T. Minamiki, Y. Hashima, Y. Sasaki, T. Minami, “An electrolyte-gated polythiophene transistor for the detection of biogenic amines in water," Chemical Communications, vol. 54, no. 50, pp. 6907-6910, 2018.

[9] C. Li, G. Shi, "Polythiophene-based optical sensors for small molecules," ACS Applied Materials \& Interfaces, vol. 5, no. 11, pp. 4503-4510, 2013.

[10] L. Torsi, A. Tafuri, N. Cioffi, M.C. Gallazzi, A. Sassella, L. Sabbatini, P.G. Zambonin, "Regioregular polythiophene field-effect transistors employed as chemical sensors," Sensors and Actuators B: Chemical, vol. 93, no. 1-3, pp. 257-262, 2003.

[11] L. Zhang, X. Hu, Z. Wang, F. Sun, D.G. Dorrell, "A review of supercapacitor modeling, estimation, and applications: A control/management perspective," Renewable and Sustainable Energy Reviews, vol. 81, pp. 1868-1878, 2018. 
[12] J.G. Ibanez, M.E. Rincón, S. Gutierrez-Granados, M.H. Chahma, O.A. Jaramillo-Quintero, B.A. Frontana-Uribe, "Conducting polymers in the fields of energy, environmental remediation, and chemical-chiral sensors," Chemical Reviews, vol. 118, no. 9, pp. 4731-4816, 2018.

[13] K.H. An, W.S. Kim, Y.S. Park, Y.C. Choi, S.M. Lee, D.C. Chung, Y.H. Lee, "Supercapacitors using single-walled carbon nanotube electrodes," Advanced Materials, vol. 13, no. 7, pp. 497-500, 2001.

[14] J.R. McDonough, J.W. Choi, Y. Yang, F. La Mantia, Y. Zhang, Y. Cui, "Carbon nanofiber supercapacitors with large areal capacitances," Applied Physics Letters, vol. 95, no. 24, pp. 243109, 2009.

[15] Y. Wang, Z. Shi, Y. Huang, Y. Ma, C. Wang, M. Chen, Y. Chen, "Supercapacitor devices based on graphene materials," The Journal of Physical Chemistry C, vol. 113, no. 30, pp. 13103-13107, 2009.

[16] X. Lu, G. Wang, T. Zhai, M. Yu, J. Gan, Y. Tong, Y. Li, "Hydrogenated $\mathrm{TiO}_{2}$ nanotube arrays for supercapacitors," Nano Letters, vol. 12, no. 3, pp. 1690-1696, 2012.

[17] S.N. Pusawale, P.R. Deshmukh, C.D. Lokhande, "Chemical synthesis of nanocrystalline $\mathrm{SnO}_{2}$ thin films for supercapacitor application," Applied Surface Science, vol. 257, no. 22, pp. 9498-9502, 2011.

[18] J.W. Lee, T. Ahn, J.H. Kim, J.M. Ko, J.D. Kim, "Nanosheets based mesoporous NiO microspherical structures via facile and template-free method for high performance supercapacitors," Electrochimica Acta, vol. 56, no. 13, pp. 4849-4857, 2011.

[19] K.M. Lin, K.H. Chang, C.C. Hu, Y.Y. Li, "Mesoporous $\mathrm{RuO}_{2}$ for the next generation supercapacitors with an ultrahigh power density," Electrochimica Acta, vol. 54, no. 19, pp. 4574-4581, 2009.

[20] B. Saravanakumar, K.K. Purushothaman, G. Muralidharan, "Interconnected $\mathrm{V}_{2} \mathrm{O}_{5}$ nanoporous network for high-performance supercapacitors," ACS Applied Materials \& Interfaces, vol. 4, no.9, pp. 4484-4490, 2012.

[21] J.G. Wang, F. Kang, B. Wei, "Engineering of $\mathrm{MnO}_{2}$-based nanocomposites for high-performance supercapacitors," Progress in Materials Science, vol. 74, pp. 51-124, 2015.

[22] T.O. Magu, A.U. Agobi, L. Hitler, P.M. Dass, “A review on conducting polymers-based composites for energy storage application,” Journal of Chemical Reviews, vol. 1, no. 1, pp. 19-34, 2019.

[23] A. Eftekhari, L. Li, Y. Yang, "Polyaniline supercapacitors," Journal of Power Sources, vol. 347, pp. 86-107, 2017.

[24] X. Wang, M. Xu, Y. Fu, S. Wang, T. Yang, K. Jiao, "A highly conductive and hierarchical PANI micro/nanostructure and its supercapacitor application," Electrochimica Acta, vol. 222, pp. 701-708, 2016.

[25] Y. Huang, H. Li, Z. Wang, M. Zhu, Z. Pei, Q, Xue, C. Zhi, "Nanostructured polypyrrole as a flexible electrode material of supercapacitor," Nano Energy, vol. 22, pp. 422-438, 2016.

[26] R.K. Sharma, A.C. Rastogi, S.B. Desu, "Pulse polymerized polypyrrole electrodes for high energy density electrochemical supercapacitor," Electrochemistry Communications, vol. 10, no. 2, pp. 268-272, 2008.

[27] A. Laforgue, P. Simon, C. Sarrazin, J.F. Fauvarque, "Polythiophene-based supercapacitors," Journal of Power Sources, vol. 80, no. 1-2, pp. 142-148, 1999. 
[28] R.B. Ambade, S.B. Ambade, R.R. Salunkhe, V. Malgras, S.H. Jin, Y. Yamauchi, S.H. Lee, "Flexible-wire shaped all-solid-state supercapacitors based on facile electropolymerization of polythiophene with ultra-high energy density," Journal of Materials Chemistry A, vol. 4, no. 19, pp. 7406-7415, 2016.

[29] D. Yiğit, M. Güllü, "Capacitive properties of novel N-alkyl substituted poly (3, 6-dithienyl-9Hcarbazole) s as redox electrode materials and their symmetric micro-supercapacitor applications," Electrochimica Acta, vol. 282, pp. 64-80, 2018.

[30] D. Yiğit, M. Güllü, "N-Substituted poly (3, 6-dithienylcarbazole) derivatives: a new class of redoxactive electrode materials for high-performance flexible solid-state pseudocapacitors," Journal of Materials Chemistry A, vol. 5, no. 2, pp. 609-618, 2017.

[31] I. Shown, A. Ganguly, L.C. Chen, K.H. Chen, "Conducting polymer-based flexible supercapacitor," Energy Science \& Engineering, vol. 3, no.1, pp. 2-26, 2015.

[32] M. Lupacchini, A. Mascitti, G. Giachi, L. Tonucci, N. d'Alessandro, J. Martinez, E. Colacino, "Sonochemistry in non-conventional, green solvents or solvent-free reactions," Tetrahedron, vol. 73, no. 6, pp. 609-653, 2017.

[33] A. Laforgue, P. Simon, C. Sarrazin, J.F. Fauvarque, "Polythiophene-based supercapacitors," Journal of Power Sources, vol. 80, no. 1-2, pp. 142-148, 1999.

[34] E. Hür, G.A. Varol, A. Arslan, "The study of polythiophene, poly (3-methylthiophene) and poly (3, 4-ethylenedioxythiophene) on pencil graphite electrode as an electrode active material for supercapacitor applications," Synthetic Metals, vol. 184, pp 16-22, 2013.

[35] J.P. Ferraris, M.M. Eissa, I.D. Brotherston, D.C. Loveday, "Performance evaluation of poly 3(phenylthiophene) derivatives as active materials for electrochemical capacitor applications," Chemistry of Materials, vol. 10, no. 11, pp. 3528-3535, 1998.

[36] M. Mastragostino, C. Arbizzani, F. Soavi, "Conducting polymers as electrode materials in supercapacitors," Solid State Ionics, vol. 148, pp. 493-498, 2002.

[37] P. Soudan, H.A. Ho, L. Breau, D. Belanger, "Chemical Synthesis and Electrochemical Properties of Poly(cyano-substituted-diheteroareneethylene) as Conducting Polymers for Electrochemical Supercapacitors," Journal of The Electrochemical Society, vol. 148, no. 7, pp. A775, 2001.

[38] K.S. Ryu, Y.G. Lee, Y.S. Hang, Y.J. Park, X. Wu, K. Wu, M.K. Kim, M.G. Kang, N.G. Park, S.H. Chang, "Poly(ethylenedioxythiopene) (PEDOT) as polymer electrode in redox supercapacitor," Electrochimica Acta, vol. 50, no. 2-3, pp. 843-847, 2004. 